\section{orm}

OAK RIDGE NATIONAL LABORATORY

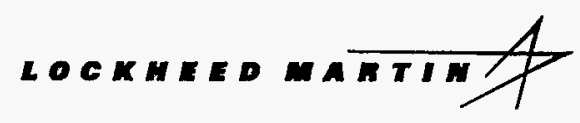

\title{
Design of Fast Tuning Elements for the ITER ICH System
}

\author{
D. W. Swain
}

R. H. Goulding 
This report has been reproduced directly from the best available copy.

Available to DOE and DOE contractors from the Office of Scientific and Technical Information, P. O. Box 62, Oak Ridge, TIN 37831; prices available from (423) 576-8401, FTS 626-8401.

Available to the public from the National Technical Information Service, U.S. Department of Commerce, 5285 Port Royal Road, Springfield, VA 22161.

This report was prepared as an account of work sponsored by an agency of the United States Government. Neither the United States Government nor any agency thereof, nor any of their employees, makes any warranty, express or implied, or assumes any legal liability or responsibility for the accuracy, completeness, or usefulness of any information, apparatus, product, or process disclosed, or represents that its use would not infringe privately owned rights. Reference herein to any specific commercial product, process, or service by trade name, trademark, manufacturer, or otherwise, does not necessarily constitute or imply its endorsement, recommendation, or favoring by the United States Government or any agency thereof. The views and opinions of authors expressed herein do not necessarily state or reflect those of the United States Government of any agency thereof. 
ORNL/TM-13230

Dist. Category UC-420

Fusion Energy Division

\title{
Design of Fast Tuning Elements for the ITER ICH System
}

D. W. Swain and R. H. Goulding

DATE PUBLISHED May 1996

Prepared for the

Office of Fusion Energy

Budget Activity AT 150403 A

\author{
Prepared by \\ OAK RIDGE NATIONAL LABORATORY \\ Oak Ridge, Tennnessee 37831-6285 \\ managed by \\ LOCKHEED MARTIN ENERGY RESEARCH CORPORATION \\ for the \\ U.S. DEPARTMENT OF ENERGY \\ under contract DE-AC05-96OR22464
}


This is the Final Report for ITER Design Task D14, "Design of Fast Tuning Elements for ICH System." It was submitted to the ITER Joint Central Team in partial fulfillment of the requirements of the Design Task, as ITER Document ITER/US/96/IVRF-01, in February 1996.

This report is an account of work assigned to the U.S. Home Team under Task Agreement No G 51 TD 03 within the agreement among the European Atomic Energy Community, the Government of Japan, the Government of the Russian Federation, and the Government of the United States of America on Cooperation in the Engineering Design Activities for the International Thermonuclear Experimental Reactor ("ITER EDA Agreement") under the auspices of the International Atomic Agency (IAEA). The report has not been reviewed by the ITER Publications Office.

This report is an account of work undertaken within the framework of the ITER EDA Agreement. Neither the ITER Director, the Parties to the ITER Agreement, the U.S. DOE, the U.S. Home Team Leader, the U.S. Home Team, the IAEA or any agency thereof, or any of their employees, makes any warranty, express or implied, or assumes any legal liability or responsibility for the accuracy, completeness, or usefulness of any information, apparatus, product, or process disclosed, or represents that its use would not infringe privately owned rights. Reference herein to any specific commercial product, process, or service by trade name, trademark, manufacturer, or otherwise, does not necessarily constitute or imply its endorsement, recommendation, or favoring by the parties to the ITER EDA Agreement, the IAEA or any agency thereof.

The views and opinions of authors expressed herein do not necessarily state or reflect those of the ITER Director, the Parties to the ITER Agreement, the U.S. DOE, the U.S. Home Team Leader, the U.S. Home Team, the IAEA or any agency thereof. 


\section{CONTENTS}

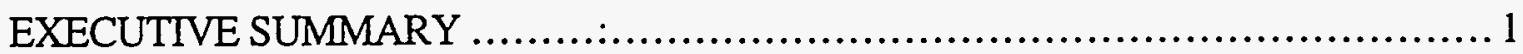

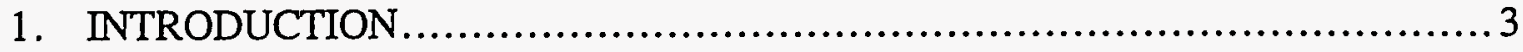

1.1 Overview................................................................... 3

1.2 Criteria for T\&M system design.......................................... 4

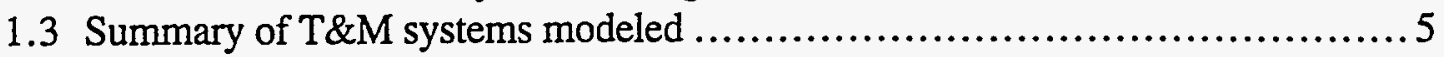

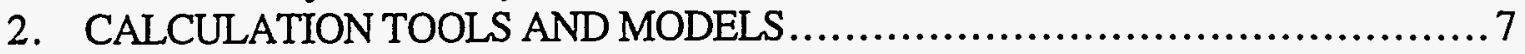

2.1 The FDAC code .......................................................... 7

2.2 Model of the ITER antenna array................................................. 7

2.3 Transmission System and Power Sources ...................................10

2.3.1 Space allocation and location of components ........................10

2.3.2 Power sources and connection to the antenna current straps................10

2.3.3 The passive ELM dump using a hybrid splitter..............................11

2.4 Loading Resistance Computations ......................................... 11

2.4.1 Plasma parameters ................................................ 12

2.4.2 Antenna geometry used in $\mathrm{R}^{\prime}$ calculations .........................12

2.4.3 Results of loading calculations .................................... 13

3. RESULTS: CONFIGURATIONS WITH NO FREQUENCY SHIFT $\ldots \ldots \ldots \ldots \ldots \ldots$

3.1 Case 1 - No PMS, decouplers far from antenna ............................13

3.2 Case 2 - PMS in Antenna, Decouplers far from Antenna (Baseline) ..............16

3.3 Case 3 - Capacitor-tuned Circuit, Decouplers far from Antenna..................20

4. RESULTS: CONFIGURATIONS WITH FREQUENCY SHIFT ...................24

4.1 Case 4 - PMS with Decouplers Near Antenna, $\Delta$ f for Matching....................24

4.1.1 Results for an uncoupled system.....................................25

4.1.2 Results for a coupled system ....................................27

4.2 Case 5 - PMS with Decouplers Near Antenna, $\Delta \mathrm{f}$ and $\Delta \mathrm{C}$ for Matching........29

5. RESULTS: SIMULATION OF ELMS IN ITER ................................30

6. RECOMMENDATION FOR R\&D TASKS........................................31 


\section{LIST OF FIGURES}

Figure $\quad$ Page

1. ITER T\&M model for four center-grounded current straps $\ldots \ldots \ldots \ldots \ldots \ldots \ldots \ldots \ldots . . . . \ldots$

2. Diagram of single strap. .................................................... 9

3. Approximate distances and clearances on the ICRF component path. ..............10

4. Loading resistance vs outer separatrix-wall gap for $\pi$ ancl $\pi / 2$ phasing between adjacent current straps...............................................13

5. Case 1. Schematic and dimensions...........................................14

6. Case 1. Voltage vs distance from the strap ground...............................15

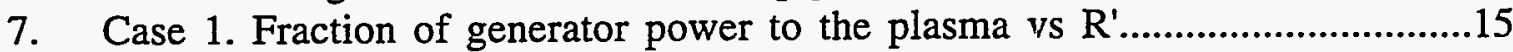

8. Case 1. Maximum voltage vs $\mathrm{R}^{\prime}$ for $12.5 \mathrm{MW}$ delivered to the plasma per

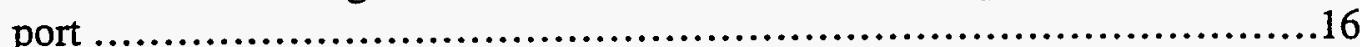

9. Case 2. Schematic and dimensions...........................................

10. Case 2. Voltage vs distance from strap ground ................................17

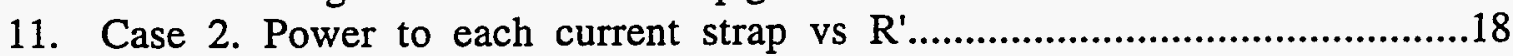

12. Case 2. Fraction of generator power to plasma vs $\mathrm{R}^{\prime}$..........................18

13. Case 2. Voltage vs distance from strap ground on the four transmission lines ......19

14. Case 2. Fraction of power to the plasma vs frequency, for $R^{\prime}=3 \Omega / m \ldots \ldots \ldots \ldots . .20$

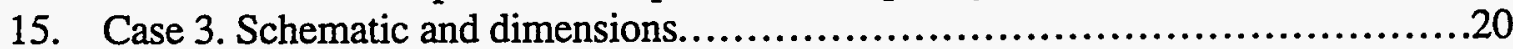

16. Case 3. Frequency bands that can be tuned by variable capacitor. .................21

17. Case 3. Voltage vs distance from strap ground for two frequencies ...............22

18. Case 3. Voltage vs distance from strap ground for two frequencies in the 40-

$\mathrm{MHz}$ band. The QWT is the same as for the $60-\mathrm{MHz}$ case. ..................22

19. Case 3. Capacitance, peak current in the capacitor, and voltage on the

capacitor...................................................................23

20. Case 4. Schematic and dimensions.........................................24

21. Case 4, uncoupled. Smith chart plots of admittance...................................25

22. Case 4, uncoupled. (a) Calculated frequency shift and (b) $|\rho|$ vs $R^{\prime}$................26

23. Case 4, uncoupled. Maximum voltage in different line segments vs $R^{\prime}$.............26

24. Case 4, coupled. (a) Calculated frequency shift and (b) $|\rho|$ at point 4 vs $R^{\prime} \ldots \ldots \ldots . .27$

25. Case 4 , coupled. Ip| vs $\mathrm{f}$ for each of the 4 coupled lines...........................28

26. Case 5. Schematic and dimensions...........................................29

27. Case 5. (a) Frequency shift for all lines, (b) capacitance values, and (c)

VSWRs vs R .........................................................29

28. Behavior of $R^{\prime}(t)$ measured on DIII-D during an ELMy H-mode discharge.........30

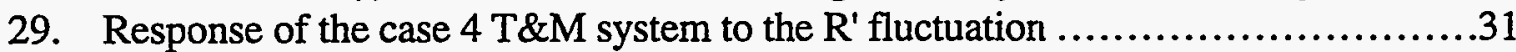




\section{EXECUTIVE SUMMARY}

The coupling between the ion cyclotron (IC) antenna and the ITER plasma (as expressed by the load resistance the antenna sees) will experience relatively fast variations due to plasma edge profile modifications. If uncompensated, these will cause an increase in the amount of power reflected back to the transmitter and ultimately a decrease in the amount of radio frequency ( $\mathrm{rf}$ ) power to the plasma caused by protective suppression of the amount of rf power generated by the transmitter. The goals of this task were to study several alternate designs for a tuning and matching (T\&M) system and to recommend some research and development (R\&D) tasks that could be carried out to test some of the most promising concepts.

Analyses of five different $T \& M$ configurations are presented in this report. They each have different advantages and disadvantages, and the choice among them must be made depending on the requirements for the IC system. Several general conclusions emerge from our study:

- The use of a hybrid splitter as a passive reflected-power dump ["edge localized mode (ELM)-dump"] appears very promising; this configuration will protect the rf power sources from reflected power during changes in plasma loading due to plasma motion or profile changes (e.g., ELM-induced changes in the plasma scrape-off region) and requires no active control of the rf system.

- Trade-offs between simplicity of design and capability of the system must be made.

- Simple system designs with few components near the antenna either have high voltages over considerable distances of transmission lines, or they are not easily tuned to operate at different frequencies (cases 1 and 2 in this report).

- Designs using frequency shifts and/or fast tuning elements can provide fast matching over a wide range of plasma loading; however, the designs studied here require components near the antenna, complicating assembly and maintenance (cases 4 and 5).

- Capacitor-tuned resonant systems may offer a good compromise (case 3).

A simulation of the ITER system response to ELMs, using loading data from DIII-

$\mathrm{D}$, was done. This indicated that the use of the passive ELM dump or frequency matching would maintain satisfactory matching.

Four R\&D tasks have been identified from this study. The primary near-term needs are:

- A test of the passive ELM dump on a real experiment. Such R\&D is proposed for DIII$D$ in the United States, and possibly ASDEX-U in Europe.

- A test of the frequency-shift matching system on a real experiment to gauge its capability to respond to ELMs.

- A test of the fast matching system using fast tunable capacitors on an operating experiment.

- The development and testing of highly reliable methods to detect arcs in the antenna and transmission system, and to discriminate between these arcs and changes in loading caused by plasma changes. 


\section{INTRODUCTION}

\subsection{OVERVIEW}

This task was a collaborative one between the United States and Europe, involving primarily R. Goulding and D. Swain [Oak Ridge National Laboratory (ORNL)] to do the modeling of the circuit response, and F. Durodie (Royal Military School, Belgium/TEXTOR), who has a fast capacitor that has been built and operated on TEXTOR. This report describes only the results from the U.S. Home Team. According to the original task agreement, the task was to consist of:

"Detailed design of one single (or a coupled pair of) tuning elements, capable of maintaining the impedance match of ITER power sources within VSWR $<1.5$ in all relevant plasma conditions. The overall time response of the system shall not be less than $50 \mathrm{~ms}$. The study should

1. Identify the most suitable technology of impedance modulation applicable over the whole ITER frequency range

2. Provide a detailed design for the tuner

3. Draft a technical specification for an R\&D task"1

Since the original assignment, two things have happened to change the task somewhat.

- The antenna geometry was changed from an in-blanket to an in-port design,

- Greater emphasis was desired to be placed on fast $(\leq 10 \mathrm{~ms})$ time response in order to protect from fast ELMs.

ELMs can cause the load resistance to increase by a factor of 4 in $<1 \mathrm{~ms}$. However, the output tube in the transmitter should be able to take short $(<10 \mathrm{~ms})$ bursts of high reflected power at the proper phase without damage, so the goal was changed to attempt to match within $10 \mathrm{~ms}$ and/or to handle the reflected power passively.

This report presents the results of modeling two main types of tuning and matching (T\&M) systems. The first type of system is essentially passive, in that if the loading resistance changes equally in the different current straps, the reflected power is absorbed in a dummy load and is not propagated back to the transmitter. The main drawback with this system is that while the transmitter output power can remain high, the power delivered to the plasma decreases during the transient.

The second type of system uses small shifts in the driving frequency $(\leq 0.4 \mathrm{MHz})$ and/or Durodie's fast capacitors (or some other fast tuning device) to quickly rematch the system during an ELM. Whether capacitors can be tuned effectively on an ELM time scale remains to be determined. However, it may be that a combination of the two techniques would work better than either separately.

Finally, this area of study is a rapidly evolving one. Work to implement better, faster T\&M systems is under study at several laboratories, and new techniques will be demonstrated in the near future on the Joint European Torus (JET), the tokamak experiment at General Atomics (DIII-D), and other tokamaks. A necessary accompaniment to faster matching is better discrimination between reflected power due to plasma load changes and reflected power due to arcs in antennas or tuning systems. Research and development (R\&D) are also underway in this area and are necessary parts of the whole. 


\subsection{CRITERIA FOR T\&M SYSTEM DESIGN}

One of the difficulties in designing a $T \& M$ system for the International Thermonuclear Experimental Reactor (ITER) has been in determining what performance criteria the system must meet. The first approach has been to demand everything (e.g., match instantaneously to all changes in loading; be able to operate at any frequency from 20 to $120 \mathrm{MHz}$; be able to change phase instantaneously between adjacent current straps; have a simple, robust system with only a few components ...). While highly desirable, it is usually impossible to meet all such criteria, and so the search for feasible solutions begins.

Below are some different criteria that could be requested. All of these criteria have been discussed as possible ones for ITER at one time or another.

Frequency range:

F1 Any frequency in 45- to $90-\mathrm{MHz}$ range at full power.

F2 A selected set of frequencies in the above range at full power.

F3 A narrow band ( $\leq 5 \mathrm{MHz}$ wide) of frequencies.

F4 One frequency or a set of discrete frequencies ( $\mathrm{n} / 2)$.

Tuning capability:

T1 Change frequency during a shot, under power.

T2 Change frequency between shots.

T3 Operate at one frequency primarily, with significant T\&M system modifications required to operate at another frequency.

Response to transient changes in loading (e.g., ELMs):

E1 Deliver full $\mathrm{rf}$ power to the plasma over a range of 4:1 transient changes in plasma loading, with very fast: $(\leq 1 \mathrm{~ms})$ rematching time.

E2 Actively rematch the if system during transient changes, and return to full power to the plasma in much less than a confinement time (e.g., 10 to $100 \mathrm{~ms}$ ).

E3 Passively protect the rf system during transient changes, and allow power to decrease during transient and return to normal when load returns to normal.

Voltages in the system:

V1 Keep voltages in the rf system at $\leq 20 \mathrm{kV}$ over most of the transmission system and T\&M network, with high voltages $(>30 \mathrm{kV})$ only in the vacuum if system in or near the antenna.

V2 Allow voltages $>30 \mathrm{kV}$ in pressurized system as well as vacuum. Component location:

C1 Keep all T\&M components (except for transmission lines) out of the pit area.

C2 Keep all except a few relatively small T\&M components out of the pit area.

C3 Put large T\&M components in pit area. 
Changes in phase between adjacent straps:

P1 Very fast $(<1 \mathrm{~ms})$ under power, with no mechanical component retuning.

P2 Much faster than L/R plasma current decay time $(\leq 100 \mathrm{~ms})$ with some mechanical retuning under power.

P3 No change in phase during a shot.

The following section is a discussion of the cases we have analyzed. As will be seen, the systems meet different criteria.

\subsection{SUMMARY OF T\&M SYSTEMS MODELED}

Many different T\&M configurations have been examined, because the FDAC code (described in Section 2) makes changes in the systems relatively easy. In this report, we present results from five particular cases.

1. No prematching stub (PMS), decouplers far from antenna (with hybrid splitter)

Pro: Simplest system.

No components near antenna.

Can be tuned to different frequencies easily.

Con: High voltage $(\geq 40 \mathrm{kV}$ ) occurs over all $\sim 50 \mathrm{~m}$ of line to T\&M area.

Power to plasma drops as $\mathrm{R}^{\prime}$ changes.

Some loss in power $(\leq 15 \%)$ at low $R^{\prime}$ values because of high VSWR in main line.

Changing phase $(\Delta \phi)$ between current straps may require retuning of major $T \& M$ components, unless decoupler position can be adjusted to be near a voltage maximum in the line.

2. PMS in antenna, decouplers far from antenna (baseline), (with hybrid splitter)

Pro: PMS provides low voltages in main transmission line (similar to violin antenna concept).

Con: Single-frequency operation unless PMS is changed, which may require remotemaintenance access to antenna.

Changing phase $(\Delta \phi)$ between current straps may require retuning of major $T \& M$ components, unless decoupler position can be adjusted to be near a voltage maximum in the line.

3. Capacitor as tuning element (with hybrid splitter)

Pro: Provides low voltages in main transmission line (similar to violin antenna concept).

Allows some tuning in bands of interest (near 40,60 , and $80 \mathrm{MHz}$ )

Con: Capacitors located near torus, outside of vacuum flange, and probably on pressurized side of vacuum window.

Changing phase $(\Delta \phi)$ between current straps may require retuning of major $T \& M$ components, unless decoupler position can be adjusted to be near a voltage maximum in the line.

4. PMS with decouplers near (but outside of) antenna, frequency shift ( $\Delta f$ ) for matching.

Pro: Can deliver full power to plasma for good range of $R^{\prime}$ change.

Can change $\Delta \phi$ without changing major $T \& M$ component tuning.

Con: Decoupler components located near antenna in remote maintenance area. 
Location of PMS on line must be changed for different frequencies.

5. PMS with decouplers near antenna, $\Delta \mathrm{f}$ and fast capacitor change $(\Delta \mathrm{C})$ for matching.

Pro: Excellent matching during $\mathrm{R}^{\prime}$ changes. Can maintain essentially full power to plasma during $\sim 6: 1$ change in loading resistance.

Can change $\Delta \phi$ without changing major $T \& M$ component tuning.

Con: Requires fast ( $\leq 10 \mathrm{~ms}$ ) capacitor tuning.

Decoupler components located near antenna in remote maintenance area.

Location of PMS on line must be changed for different frequencies.

Table 1 is a comparison matrix showing the criteria options that each of the systems satisfies.

Table 1. Criteria satisfied by the different cases modeled

\begin{tabular}{|c|c|c|c|c|c|c|}
\hline & $\begin{array}{c}\text { Case } \\
\end{array}$ & 1 & 2 & 3 & 4 & 5 \\
\hline F1 & Any frequency in $45-$ to $90-\mathrm{MHz}$ range & $\overline{\mathrm{X}}$ & & & & \\
\hline $\mathrm{F} 2$ & A selected set of frequencies (bands) & & & $\mathrm{X}$ & & \\
\hline F3 & A narrow band of frequencies & & & & & \\
\hline F4 & $\begin{array}{l}\text { One frequency or a set of discrete } \\
\text { frequencies }(n \lambda / 2)\end{array}$ & & $\mathrm{X}$ & & $X$ & $\mathrm{X}$ \\
\hline T1 & Change frequency during a shot & & & & & \\
\hline $\mathrm{T} 2$ & Change frequency between shots & $\mathrm{X}$ & & $\mathrm{X}$ & & \\
\hline T3 & $\begin{array}{l}\text { One frequency primarily, significant } \\
\text { modifications to change frequency }\end{array}$ & & $X$ & & $X$ & $\mathrm{X}$ \\
\hline$\overline{\text { E1 }}$ & $\begin{array}{l}\text { Full rf power over } 4: 1 \text { loading changes, } \\
\text { very fast }(\leq 1 \mathrm{~ms}) \text { response time }\end{array}$ & & & & $\bar{X}$ & \\
\hline E2 & $\begin{array}{l}\text { Actively rematch during transients, } \\
\text { return to full power in } 10 \text { to } 100 \mathrm{~ms}\end{array}$ & & & & & $\mathrm{X}$ \\
\hline E3 & $\begin{array}{l}\text { Passively protect rf system during } \\
\text { transients, decrease power during } \\
\text { transient }\end{array}$ & $\mathrm{X}$ & $X$ & $\mathrm{X}$ & & \\
\hline$\overline{\mathrm{V} 1}$ & $\begin{array}{l}\text { Voltage } \leq 20 \mathrm{kV} \text { over most of system, } \\
>30 \mathrm{kV} \text { only in vacuum }\end{array}$ & & $\bar{X}$ & & & \\
\hline V2 & $\begin{array}{l}\text { Voltage }>30 \mathrm{kV} \text { in pressurized system } \\
\text { as well as vacuum }\end{array}$ & $X$ & & $X$ & $X$ & $X$ \\
\hline$\overline{\mathrm{C} 1}$ & All T\&M components out of the pit area & $\bar{X}$ & $\bar{X}$ & & & \\
\hline $\mathrm{C} 2$ & $\begin{array}{l}\text { All except a few relatively small } \\
\text { components out of the pit area }\end{array}$ & & & $\mathrm{X}$ & & \\
\hline C3 & Large T\&M components in pit area & & & & $\mathrm{X}$ & $X$ \\
\hline$\overline{\mathrm{P} 1}$ & $\begin{array}{l}\text { Very fast }(<1 \mathrm{~ms}) \text { phase shift under } \\
\text { power }\end{array}$ & & & & $\mathrm{X}^{\mathrm{a}}$ & $\mathrm{X}^{\mathrm{a}}$ \\
\hline P2 & $\begin{array}{l}\text { Phase shift much faster than L/R time } \\
(\leq 100 \mathrm{~ms}) \text { under power }\end{array}$ & & & & & \\
\hline P3 & No change in phase during a shot & $\mathrm{X}^{\mathrm{b}}$ & $X^{b}$ & $X^{b}$ & & \\
\hline
\end{tabular}




\section{CALCULATION TOOLS AND MODELS}

\subsection{THE FDAC CODE}

The FDAC code ${ }^{2}$ is a powerful tool that can be used to model coupled rf circuits, especially the sorts of coupled antenna and transmission line systems commonly found in contemporary IC heating systems. The code is written in the PV-WAVETM programming environment, a high-level programming and data display system. ${ }^{3}$ For the results shown in this report, PV-WAVE was run on an IBM RISC workstation.

FDAC consists of a number of modules that model common rf circuit components (e.g., lossy transmission lines, coupled transmission lines, inductances, capacitors, resistors). These can be combined in a user-friendly way to generate an electrical circuit model of considerable complexity. The code can be used to simultaneously solve for several variables (e.g., line or stub lengths and capacitor settings) specified by constraint equations, such as all transmitter powers being equal with no reflected power. The results of changes in loading resistance, frequency, or component values on quantities of interest (e.g., maximum voltage in the system, VSWR) can easily be plotted for cases of interest.

Figure 1 shows a typical model of the ITER antenna array and associated T\&M system. The model shown consists of four current straps, each grounded at the center and driven at both ends. T\&M circuits external to the antenna consist of a line stretcher and stub in each leg of the transmission lines. Passive if decoupler circuits ("Decoupler" in the figure) are between the transmission lines driving adjacent strap segments. Sometimes an additional component, a susceptance nuller ("SN" in the figure) is installed at the decoupler/transmission line junction; this can be an adjustable stub, or possibly a capacitor.

The prematching stub (PMS) shown in Fig. 1 can either be inside the antenna itself, corresponding to the present baseline ITER antenna design or can be outside the antenna so that it can be more accessible for maintenance and tuning. Cases were run that had no PMS, that had PMSs inside the antenna, and that had PMSs outside the antenna.

A power splitter is used to connect the T\&M system for the top and bottom segments of a strap to a single if power source. For all cases considered here, a hybrid power splitter was used. ${ }^{4}$ The fourth port of the splitter was connected to a dummy load, as shown in the figure.

Several specific cases have been analyzed for this general situation. More details of the models used for the antenna, the decouplers, and the power splitters are given in the following sections.

\subsection{MODEL OF THE ITER ANTENNA ARRAY}

The present ITER antenna design consists of an array that can be inserted through a main horizontal port. The port dimensions are approximately $1.6 \mathrm{~m}$ toroidally $\times 2.6 \mathrm{~m}$ poloidally. There are eight center-grounded current straps in a 4 (toroidally) $\times 2$ (poloidally) array. For the purposes of this calculation, we assume negligible coupling between current straps in the top and bottom arrays.

Thus, the antenna array in one port consists of two configurations as shown in Fig. 1, one above the other. This is the configuration that we will analyze in the remainder 
of this report. The total power that can be delivered from a single port is twice the power that will be delivered from the array shown in Fig. 1.

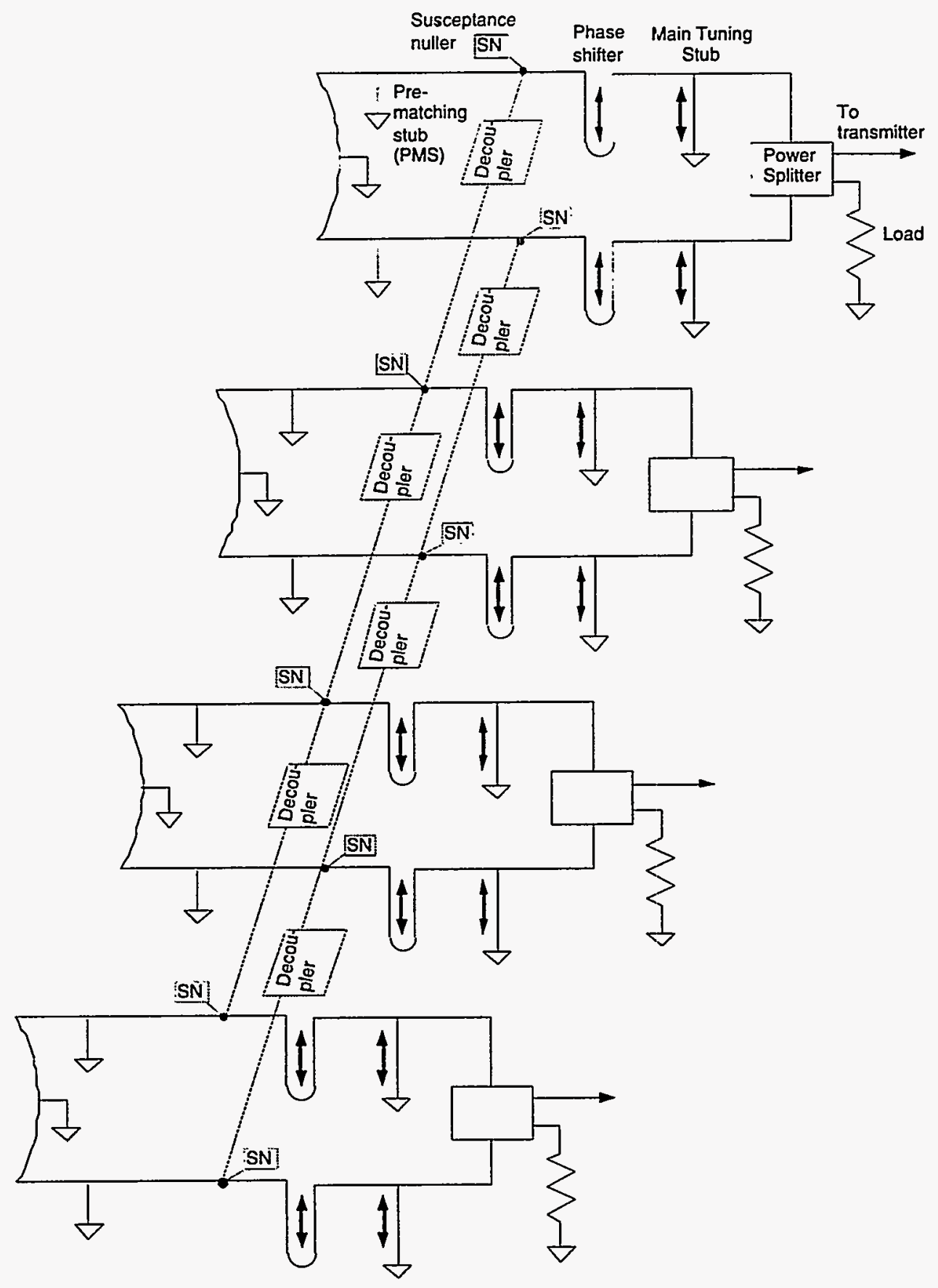

Fig. 1. TTER T\&M model for four center-grounded current straps in the top half of an ITER in-port antenna. 
Figure 2 shows one grounded current strap, with characteristic parameters for the strap. The total strap height is approximately $1.2 \mathrm{~m}$, so the distance from ground to the end of the radiating part of the current strap is $0.6 \mathrm{~m}$. The electrical model of the current strap is characterized as a lossy transmission line. Based on earlier calculations, ${ }^{5}$ the current strap can be modeled with the following parameters:

$$
\begin{array}{ll}
Z_{\text {strap }}=40 \Omega & \text { Characteristic impedance of the line } \\
\beta=0.7 & \text { Relative phase velocity of wave on strap }\left(=v_{\text {phase }} / c\right) \\
R^{\prime}=2-12 \Omega / m & \text { Plasma loading resistance per unit length }
\end{array}
$$

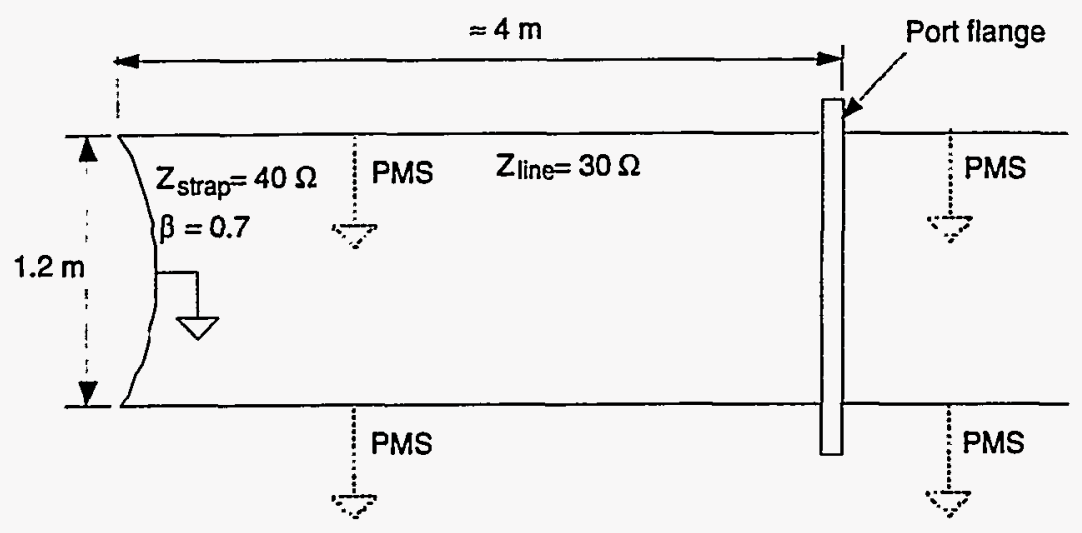

Fig. 2. Diagram of single strap. Possible locations of a PMS are shown by the dashed lines.

The plasma loading resistance depends on the phase between adjacent current straps, plasma position, density profile, and frequency. $R^{\prime}$ values for the latest design of the ITER antenna are discussed below.

From the values of $Z_{\text {strap }}$ and $\beta$, the characteristic inductance $L^{\prime}$ and capacitance $C^{\prime}$ per unit length of the strap can be calculated. In addition to the self-inductance, the current straps have mutual inductances. The coupling coefficient between straps will depend on the geometry of the straps and the septum separating them, and these dimensions have not been determined yet. Based on calculations of similar arrays, ${ }^{6}$ we have chosen mutual inductances so that $L_{12}^{\prime} / L_{11}^{\prime} \approx 0.1$, and $L_{13}^{\prime} / L_{11}^{\prime} \approx 0.01$. These values are typical, we think, of the values that are likely to be encountered. We assume further that $L_{12}^{\prime}=L_{23}^{\prime}=$ $\mathrm{L}_{34}$ and $\mathrm{L}_{13}=\mathrm{L}_{24}$.

The transmission line from the end of the current strap through the vacuum vessel port to the outside of the port flange is generally taken to be a $30-\Omega$ transmission line (with $\beta=1.0$ ); losses in this line are taken as $\mathrm{R}^{\prime}$ line $\approx 0.02 \Omega / \mathrm{m}$. As can be seen from Fig. 2 , the distance from the end of the current strap to the outside of the port flange is at least $4 \mathrm{~m}$. For the case of an external PMS, we assume that no T\&M components can be attached any nearer than that distance. Two possible locations for a PMS (one internal and one external to the antenna structure) are shown schematically as dashed elements in the figure. 


\subsection{TRANSMISSION SYSTEM AND POWER SOURCES}

\subsubsection{Space allocation and location of components}

Figure 3 [from G. Bosia, ITER Joint Central Team (ICT)] shows the approximate dimensions allocated to the ion cyclotron range of frequencies (ICRF) system components. From an installation and maintenance standpoint, it would be best to eliminate any major tuning components from the area just outside the cryostat where the remote handling transfer cask will have to be placed if an antenna is to be rernoved; this will minimize the amount of remote-maintenance connection of ICRF components. However, there is a tradeoff between simple maintenance and improved if operation.

The installation of $T \& M$ components near the vacuum vessel flange will entail their connection to the vacuum portion of the transmission line. It would be desirable to avoid this if possible, also to simplify installation and maintenance.

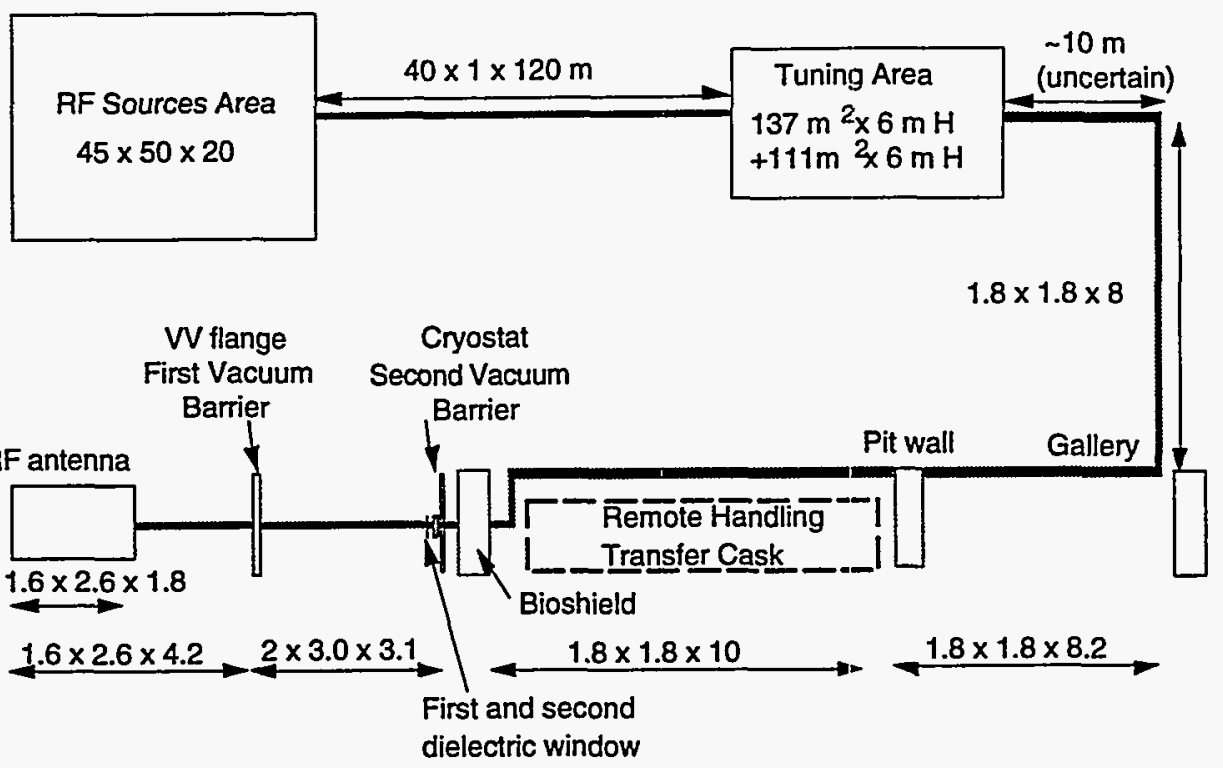

Fig. 3. Approximate distances and clearances on the ICRF component path. Source: G. Bosia, JCT

Finally, T\&M components can be installed in the antenna itself. This would be disadvantageous for maintenance, but it could offer some advantages for power handling or versatility of the rf system.

One of the purposes of this report is to examine several T\&M systems with components both near and far away from the antenna/ remote handling areas and to provide information to more quantitatively evaluate the trade-offs between maintenance simplicity on the one hand and If flexibility or power-handling capability on the other.

\subsubsection{Power sources and connection to the antenna current straps}

The present baseline design of the IC system consists of antennas in four ports. The total rf system is required to deliver $50 \mathrm{MW}$ of power to the plasma or $12.5 \mathrm{MW}$ per port. 
Each antenna consists of 8 center-grounded current straps, with each strap fed at both ends, for a total of 16 feed lines emerging from each antenna. Therefore, the power to the plasma that each feed line must deliver is approximately $0.8 \mathrm{MW}$.

The transmission lines outside the vacuum flange are modeled as $225-\mathrm{mm}$ (9-inch) standard $30-\Omega$ lines, with a copper center conductor and aluminum outer conductor. The calculated loss resistance in these lines is $R^{\prime} \approx 0.005 \Omega / \mathrm{m}$ at $60 \mathrm{MHz}$. These calculations include a $30 \%$ increase over the nominal resistance of copper and aluminum, which is added to account for bellows, flanges, etc.

The if power sources in the $40-$ to $90-\mathrm{MHz}$ range (as used on many present-day fusion devices) can deliver up to about $2 \mathrm{MW}$ per source into a mismatched load (VSWR up to 1.5). For the most efficient utilization of rf sources, each source should drive two feed lines. A power splitter of some sort is needed between each source and the feed lines. A hybrid splitter, such as is used on DIII-D, is used to split the power in all the circuits considered in this report.

\subsubsection{The passive ELM dump using a hybrid splitter}

The hybrid splitter has an additional advantage because it can be used to protect the rf sources from reflected power, if certain conditions are met in the design of the system:

1. Path lengths from the two output ports of the hybrid splitter are equal from the splitter to the current straps they are driving.

2. The changes in antenna loading ( $R^{\prime}$ and $L^{\prime}$ ) for the two straps caused by changes in the plasma are the same for both lines.

When these conditions are satisfied, the change in loading of the two straps will cause equal amounts of reflected power to be sent back to the hybrid splitter. Because of the equal path lengths, the phase of the reflected power that reaches the hybrid splitter is such that it will all be transferred to the dump resistor attached to the fourth port of the splitter.

In practice, we propose to meet these criteria by using the two outputs from a single hybrid splitter to drive the feed lines that are attached to the top and bottom of a single center-grounded current strap. Because of the similar electrical characteristics of the top and bottom halves of the same strap, they should see approximately the same loading from the plasma, and their interactions with other antenna components (side walls, Faraday shields, other straps) should be approximately the same.

A potential objection to this is that the outputs of a hybrid splitter have a phase shift of $\pi / 2$ relative to each other. Thus, the top and bottom of the strap will be driven with a phase difference of $\pi / 2$ rather than the more conventional $\pi$ (which will make the current in the top and bottom of the strap flow in the same direction as seen from the plasma). However, calculations of plasma loading for straps with $\pi / 2$ poloidal phasing indicate that the loading may be comparable to the usual case of $\pi$ phasing if the phasing (top to bottom) is chosen correctly. ${ }^{7}$ This mode of operation needs to be tested on a real machine.

\subsection{LOADING RESISTANCE COMPUTATIONS}

The plasma loading resistance is calculated using the RANT3D code. ${ }^{8}$ This code has demonstrated the ability to calculate loading resistance values in close agreement with values measured on both Tokamak Fusion Test Reactor (TFTR) ${ }^{8}$ and DIII-D, ${ }^{9}$ when given 
accurate antenna geometry information and density profile data (for these experiments, the edge density profile was measured using a microwave reflectometer mounted adjacent to the antenna). This code uses slab geometry and assumes that the wave, once launched into the plasma, is absorbed (i.e., reflections of the wave from the far side of the plasma are not considered in this analysis).

\subsubsection{Plasma parameters}

The plasma parameters used in this analysis were taken from the ITER Physics Design Description Document, Sect. 1.9 (June 1995) definition of the ignited plasma (Table 2).

Table 2. Plasma parameters for the ITER. ignited case

\begin{tabular}{lc}
\hline Toroidal field on axis & $6 \mathrm{~T}$ \\
Plasma current & $21 \mathrm{MA}$ \\
Central plasma density & $1.36 \times 10^{20} \mathrm{~m}^{-3}$ \\
Edge plasma density & $1.1 \times 10^{20} \mathrm{~m}^{-3}$ \\
Edge plasma e-folding distance, $\lambda$ & $0.02 \mathrm{~m}$ \\
Core profile exponent, $\alpha_{\mathrm{n}}$ & 0.26 \\
\hline
\end{tabular}

The density profile inside the separatrix is given by $n(r)=\left(n_{e o}-n_{e d g e}\right)\left[1-(r / a)^{2}\right]_{n}^{\alpha}$ $+n_{\text {edge}}$; outside the separatrix it is given by $n(r)=n_{\text {edge }} \exp [-(r-a) / \lambda]$. The gap between the first wall and the current strap, containing the Faraday shield, is assumed to have negligible plasma in it.

\subsubsection{Antenna geometry used in $\mathbf{R}^{\prime}$ calculations}

A baseline antenna and plasma geometry was defined based on the latest antenna design drawings from the JCT. ${ }^{10}$ Dimensions are given in Table 3. The antenna dimensions have been changed somewhat from earlier calculations. ${ }^{11}$ In particular, the antenna width has been reduced to fit into the narrower port ( $1.6 \mathrm{~m}$ wide); this has resulted in somewhat lower values of $R$ '.

Table 3. Baseline antenna geometry

\begin{tabular}{lc}
\hline Cavity depth & $32 \mathrm{~cm}$ \\
Distance from first wall to Faraday shield front & $1 \mathrm{~cm}$ \\
Faraday shield thickness & $3 \mathrm{~cm}$ \\
Distance from first wall to strap front & $6 \mathrm{~cm}$ \\
Distance from first wall to septum & 9 and $16 \mathrm{~cm}$ \\
Thickness of straps & $5 \mathrm{~cm}$ \\
Strap width & $18 \mathrm{~cm}$ \\
Cavity width & $31 \mathrm{~cm}$ \\
Center-to-center distance between straps & $38 \mathrm{~cm}$
\end{tabular}




\subsubsection{Results of loading calculations}

Figure 4 shows the values of $R^{\prime}$ calculated for different gaps and phasings. For $\pi / 2$ phasing, a $15-\mathrm{cm}$ gap (the nominal value) gives $R^{\prime} \approx 3.4 \Omega / \mathrm{m}$ with a $9-\mathrm{cm}$ distance from the first wall to the start of the septa between adjacent current straps. With a 16-cm septum distance, $R^{\prime}$ increases to $5.3 \Omega / \mathrm{m}$. As will be seen in the calculations in the next sections, this increase in $R^{\prime}$ will allow significantly reduced voltages in the rf system.

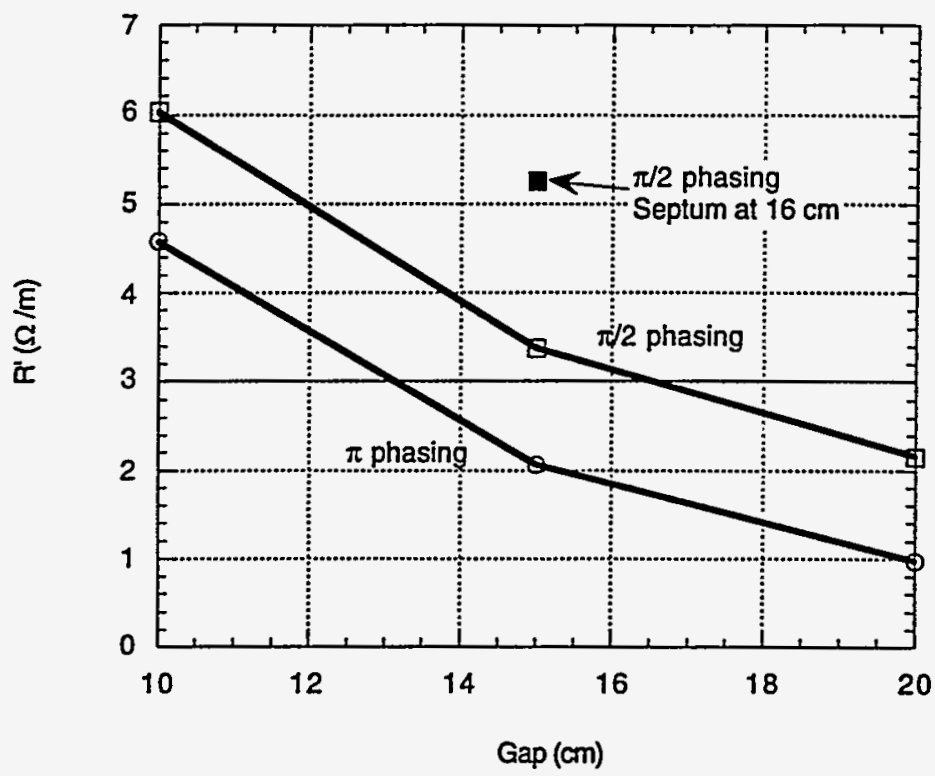

Fig. 4. Loading resistance vs outer separatrix-wall gap for $\pi$ and $\pi / 2$ phasing between adjacent current straps. Open points are with distance from first wall to septum $\left(\mathrm{x}_{\text {septum }}\right)=$ $9 \mathrm{~cm}$; solid point is with $x_{\text {septum }}=16 \mathrm{~cm}$.

\section{RESULTS: CONFIGURATIONS WITH NO FREQUENCY SHIFT}

Results have been calculated for a nominal frequency of $60 \mathrm{MHz}$. This frequency is the one of greatest interest, both for heating ( $2 \omega \mathrm{T})$ and current drive (at about $63 \mathrm{MHz}$ ) for the usual ITER design parameters.

To calculate voltages and power flow in a given circuit configuration with the lossy transmission line models used here, the value of $\mathrm{R}^{\prime}$ must be specified. Based on the results of the previous section, the lowest value of $R^{\prime}$ was chosen to be $3 \Omega / m$. For most cases presented here, the $T \& M$ circuits were initially tuned to optimize the match at this value of loading. The results from each of the different circuit configurations are discussed in the following sections.

\subsection{CASE 1 - NO PMS, DECOUPLERS FAR FROM ANTENNA}

This is the simplest configuration, with no T\&M components near the antenna. It has the advantage that the system can be tuned to any frequency in the range of the transmitters. There is about $46 \mathrm{~m}$ of $30-\Omega$ coax between each current strap and the 
decoupler, which is located in the tuning area shown in Fig. 3. A single-line schematic of this simple configuration is shown in Fig. 5.

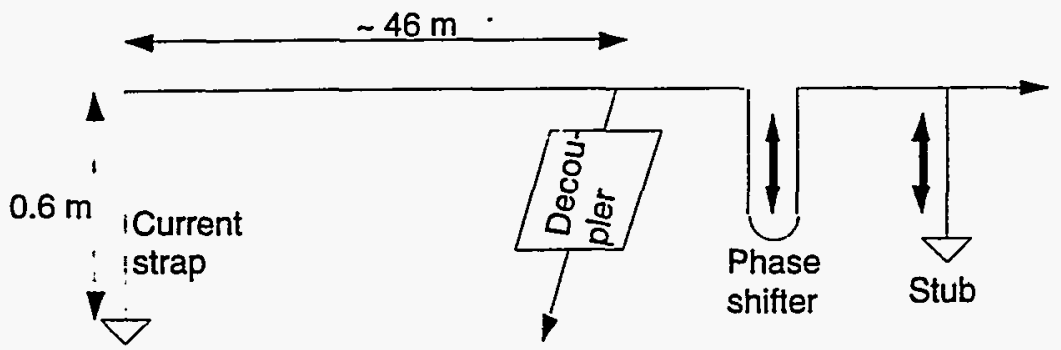

Fig. 5. Case 1. Schematic and dimensions.

Figure 6 shows the voltage on the four transmission lines feeding the top antenna current straps as a function of position from the strap ground, for the case with $R^{\prime}=3 \Omega / m$ from the plasma and the antenna delivering $12.5 \mathrm{MW}$ to the plasma. Peak voltage is about $42 \mathrm{kV}$. This figure illustrates the main disadvantage of this configuration, which is that the entire $46 \mathrm{~m}$ of transmission line operates at high VSWR, with a large number of highvoltage regions in the line.

For this case, there are significant losses in the long sections of transmission line because of the high VSWR. Figure 7 shows the efficiency of the T\&M system (defined as the power to the plasma divided by the power from the generators) for interstrap phasing of $\pi / 2$. The dashed line in the figure shows the efficiency as a function of $R^{\prime}$ when the $T \& M$ system is matched for each value of $R^{\prime}$. This indicates that for $R^{\prime}=3 \Omega / m$ (for example) about $87 \%$ of the power from the generators goes to the plasma. The rest is dissipated in losses in the T\&M system, primarily in the long transmission line. As $\mathrm{R}^{\prime}$ increases, the efficiency increases.

The solid line in Fig. 7 shows the efficiency of the system when it is tuned to a perfect match for $R^{\prime}=3 \Omega / \mathrm{m}$, but the tuning is not changed as $R^{\prime}$ changes. As $R^{\prime}$ increases, the reflected power from the T\&M system increases. We assume that the system is configured so that the hybrid splitter can be used as a passive ELM dump, as described earlier, so that this power is dissipated in the load resistor of the power splitter shown in Fig. 1. This figure indicates that for a $4: 1$ change in $R^{\prime}$ (from 3 to $12 \Omega / m$ ), the fraction of power going to the plasma only changes from $87 \%$ to $72 \%$ of the generator power. For a transient change in $\mathrm{R}^{\prime}$, this momentary power decrease may be acceptable. 


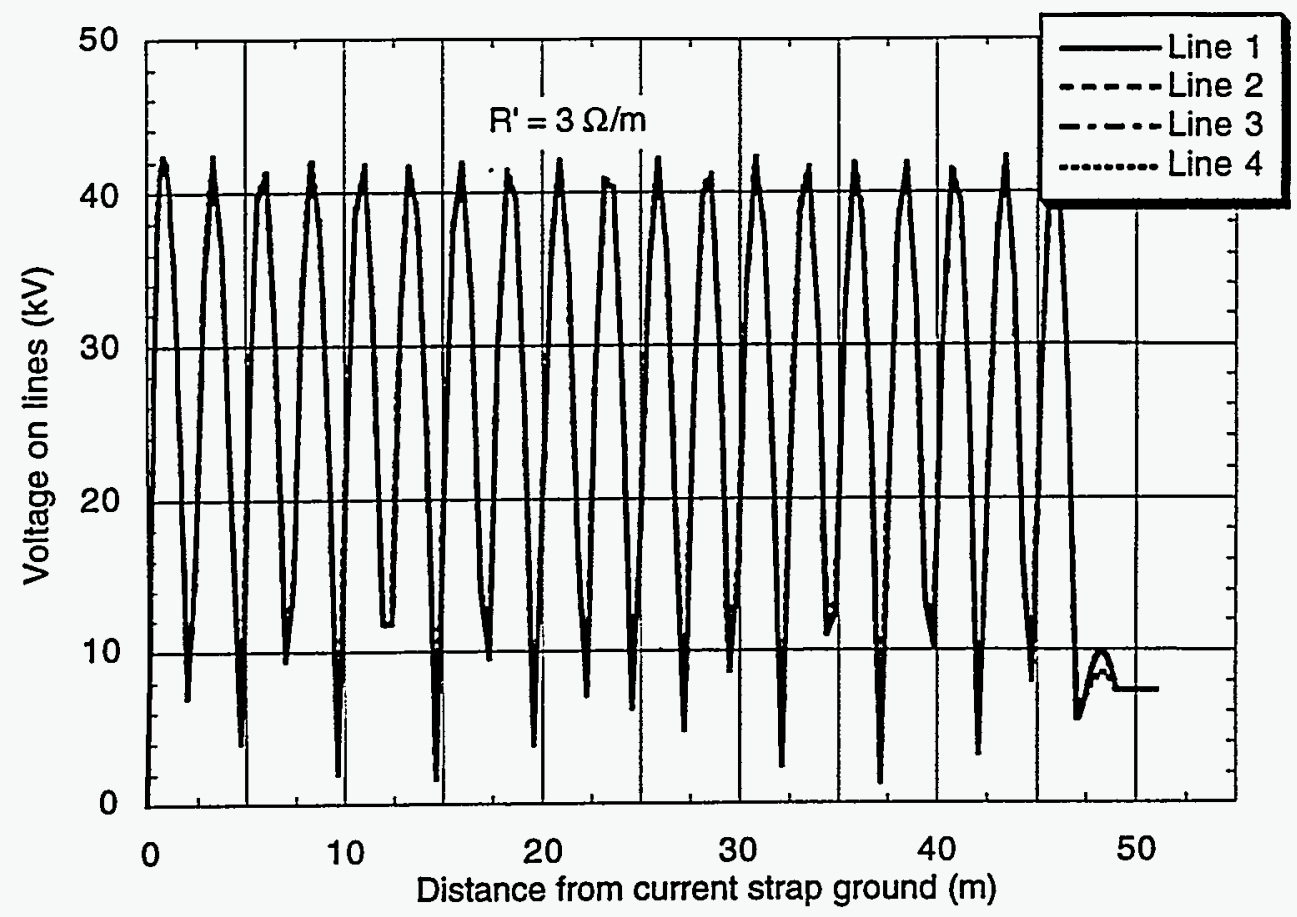

Fig. 6. Case 1. Voltage vs distance from the strap ground for the four transmission lines for $\mathrm{R}^{\prime}=3 \Omega / \mathrm{m}$, and $\Delta \phi=\pi / 2$.

Decouplers (with susceptance nullers) are located at $x \approx 47 \mathrm{~m}$.

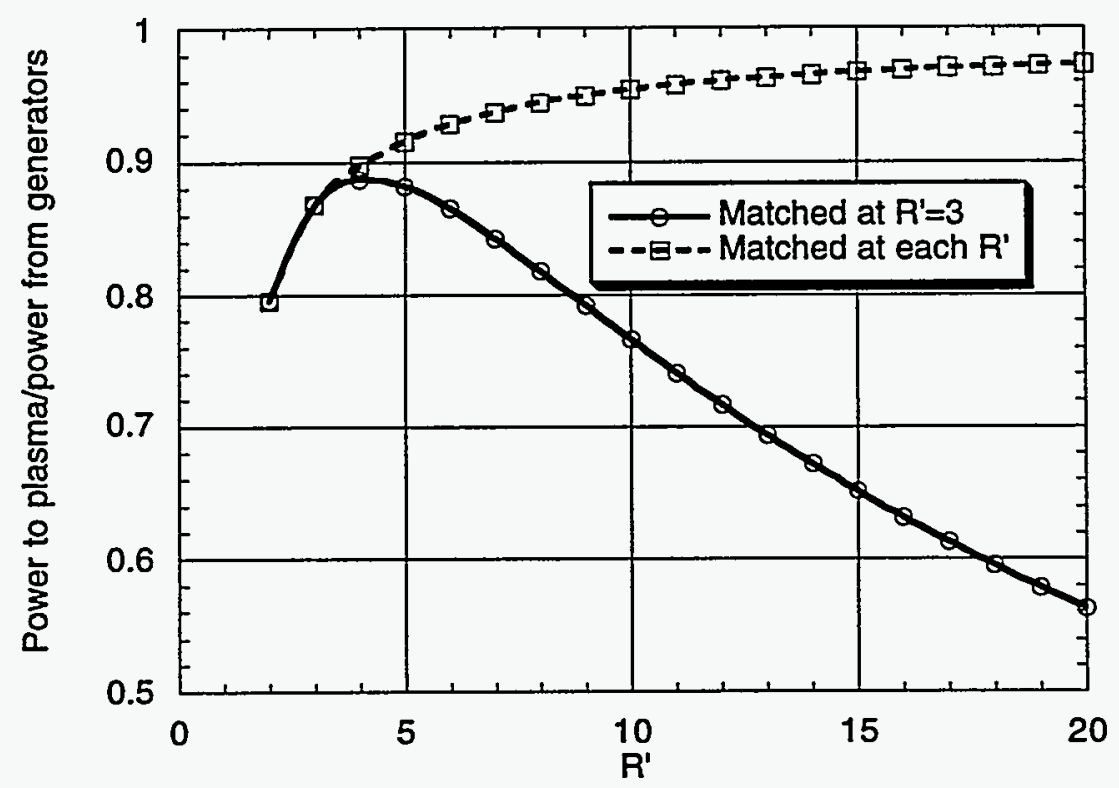

Fig. 7. Case 1. Fraction of generator power to the plasma vs R'.

Figure 8 shows the maximum voltage that occurs anywhere in the transmission system as a function of R', for a total power of $12.5 \mathrm{MW}$ per port delivered to the plasma. For $R^{\prime}=3 \Omega / \mathrm{m}$, the maximum voltage is $42 \mathrm{kV}$, but it decreases rapidly as $R^{\prime}$ is increased. For $R^{\prime}=5 \Omega / \mathrm{m}$, it is less than $35 \mathrm{kV}$. This figure is of more general applicability than just 
for this T\&M circuit configuration. Because the first high-voltage point occurs before any $T \& M$ component, this curve is generally valid independent of the specific $T \& M$ circuit.

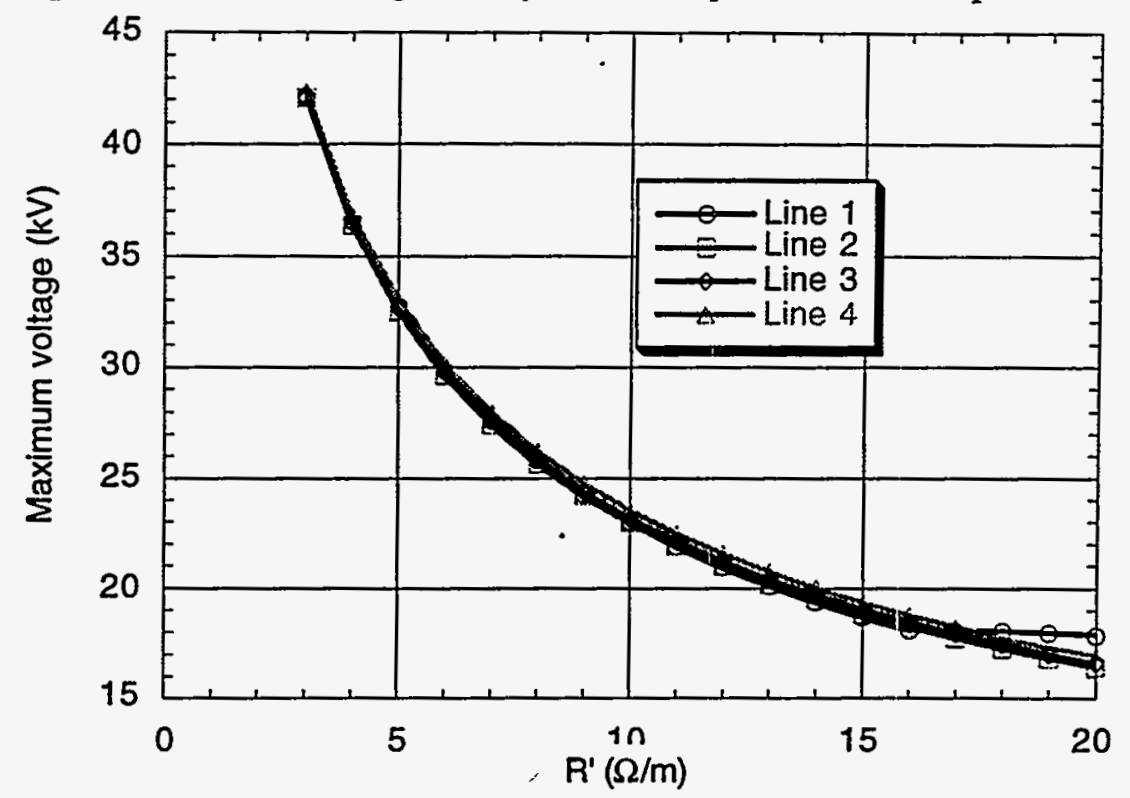

Fig. 8. Case 1. Maximum voltage vs R' for $12.5 \mathrm{MW}$ delivered to the plasma per port .

In general, changing the interstrap phasing will not be possible without retuning the decouplers. However, if the decoupler connection to the main transmission line is located at or near a voltage maximum in the main line, then the system is insensitive to phase, and fast phase changes could be done under power during a shot. For the line lengths used in these calculations, this will occur at frequency intervals of about every $3 \mathrm{MHz}$. To allow fast phase shifting at any frequency, an additional phase shifter will be needed between the antenna and the decoupler connection.

\subsection{CASE 2 - PMS IN ANTENNA, DECOUPLERS FAR FROM ANTENNA (BASELINE)}

This is the current baseline case; a schematic is shown in Fig. 9.

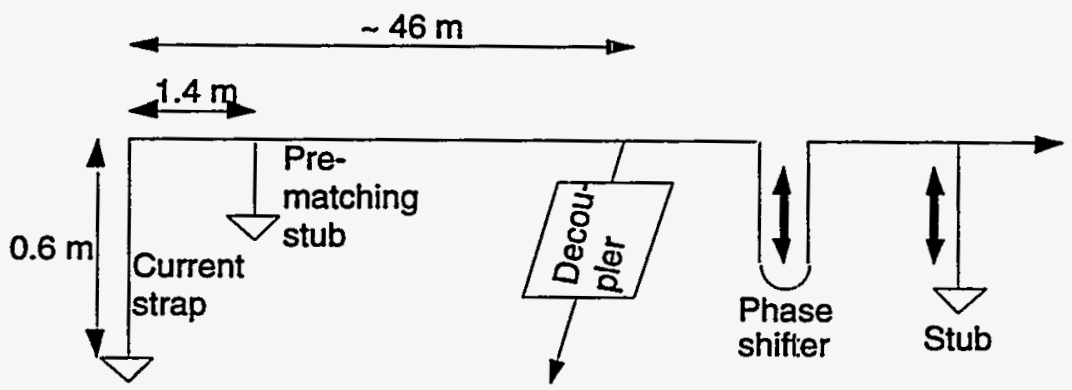

Fig. 9. Case 2. Schematic and dimensions.

It has a PMS inside the antenna, located about $1.4 \mathrm{~m}$ from the top of the current strap. The position of the PMS and the length of the stub were chosen so that (at $60 \mathrm{MHz}$ ) the current strap/transmission line section/PMS is resonant (i.e., the total electrical length is exactly 
$\lambda / 2$, and a real impedance is seen looking into this circuit). Furthermore, the length was chosen so that for $R^{\prime}=3 \Omega / \mathrm{m}$, the impedance seen is exactly $30 \Omega$, for the simplified case of no mutual coupling between current straps.

Figure 10 shows the voltage as a function of distance from the strap ground for four coupled straps, for $R^{\prime}=3 \Omega / \mathrm{m}$. The maximum voltage, located near the current strap, is again about $42 \mathrm{kV}$.

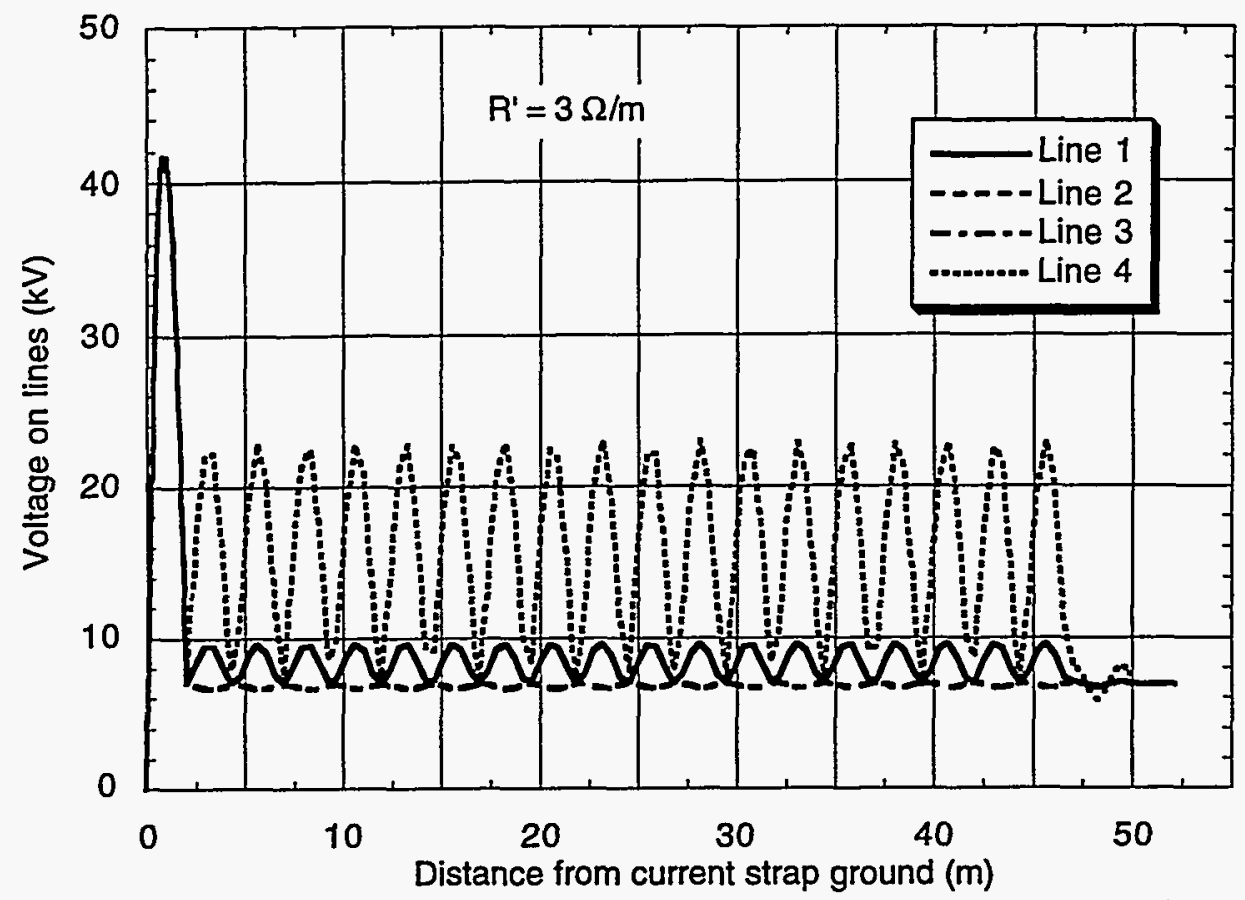

Fig. 10. Case 2. Voltage vs distance from strap ground on the four transmission lines for $\mathrm{R}^{\prime}=3 \Omega / \mathrm{m}$ at $60 \mathrm{MHz}$.

For $x \geq 2 \mathrm{~m}$, the flat voltage vs $\mathrm{x}$ for the inner straps indicates that the addition of the PMS has worked well, and these straps are well-matched to the lines. However, the outer straps are not matched exactly, as can be seen in the figure from the voltage variations on these lines. This is due to the interstrap coupling. Even so, the maximum voltage on the worst line before the PMS is only about $23 \mathrm{kV}$, about a factor of 2 reduction from the peak before the PMS.

Figure 11 shows the power flow down each of the four lines vs R', for a constant total power of 3.125 MW (i.e., 12.5 MW/port). Power flow to the first strap is negative for $R^{\prime} \leq 5 \Omega / \mathrm{m}$, demonstrating the necessity of decouplers in the T\&M circuit. 


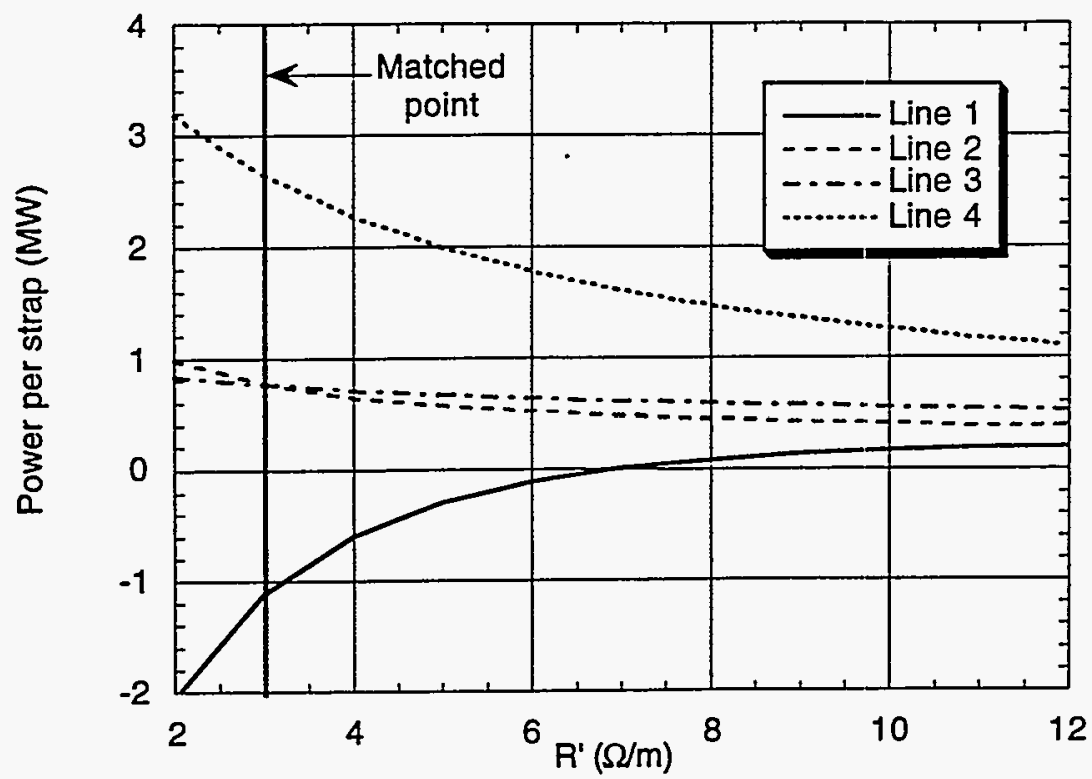

Fig. 11. Case 2. Power to each current strap vs R'.

The efficiency of this circuit is shown in Fig. 12. At the matched point, the efficiency is almost $98 \%$ because of the relatively short region with a large VSWR. As R' increases, the efficiency drops (again assuming the reflected power winds up in the hybrid splitter dump resistor). However, about $70 \%$ of the generator power will be deposited in the plasma at $R^{\prime}=12 \Omega / \mathrm{m}$.

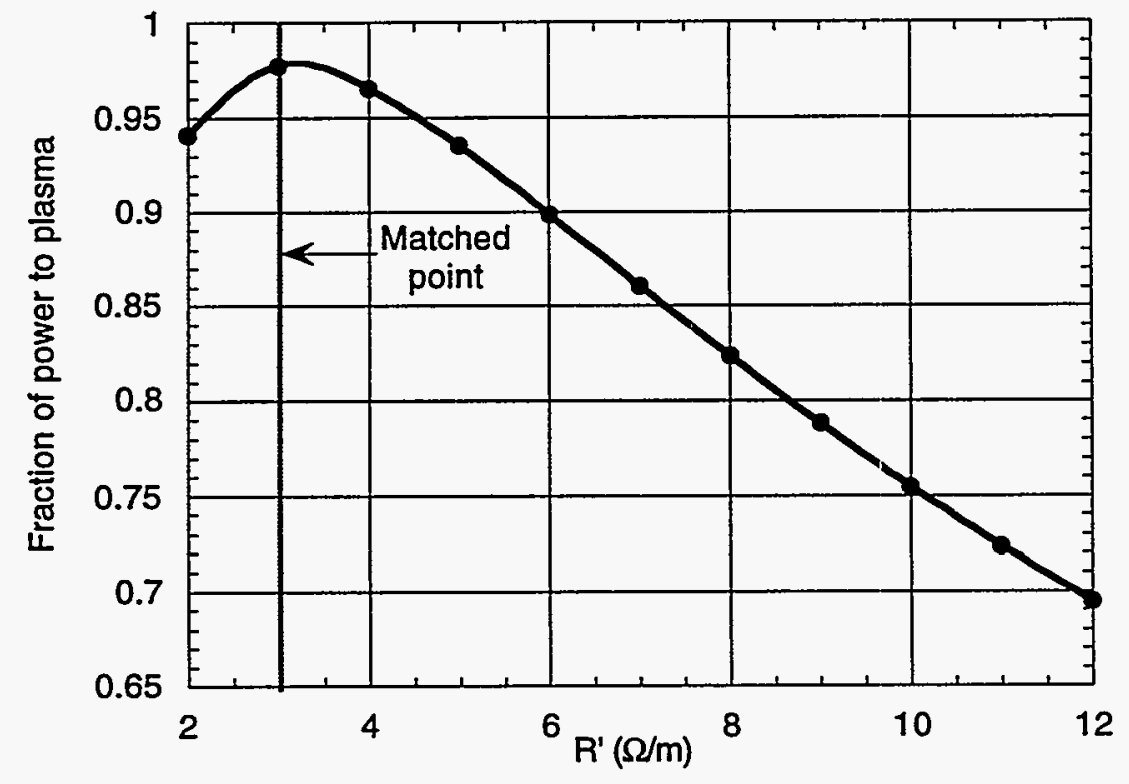

Fig. 12. Case 2. Fraction of generator power to plasma vs R'.

For $R^{\prime}=12 \Omega / m$, the voltage pattern on the transmission lines is changed to that shown in Fig. 13. For this, case, the generator power is $3.125 \mathrm{MW}$, and about $30 \%$ of that is being lost in the transmission line and load on the hybrid splitter (from Fig. 12). However, the peak voltage anywhere in the system is relatively low, $\leq 20 \mathrm{kV}$. If there is 
sufficient total power available, more power can be demanded from the generators to restore the power to the plasma to its desired value. For $12.5 \mathrm{MW} /$ port to the plasma with this value of $R^{\prime}$, the total power from the generators would have to be almost $18 \mathrm{MW}$ and would result in a peak voltage in the line of about $24 \mathrm{kV}$. Increasing the source power during a transient might be a viable way to keep the power more nearly constant in the presence of $R^{\prime}$ fluctuations, if the passive ELM dump with a hybrid splitter is used.

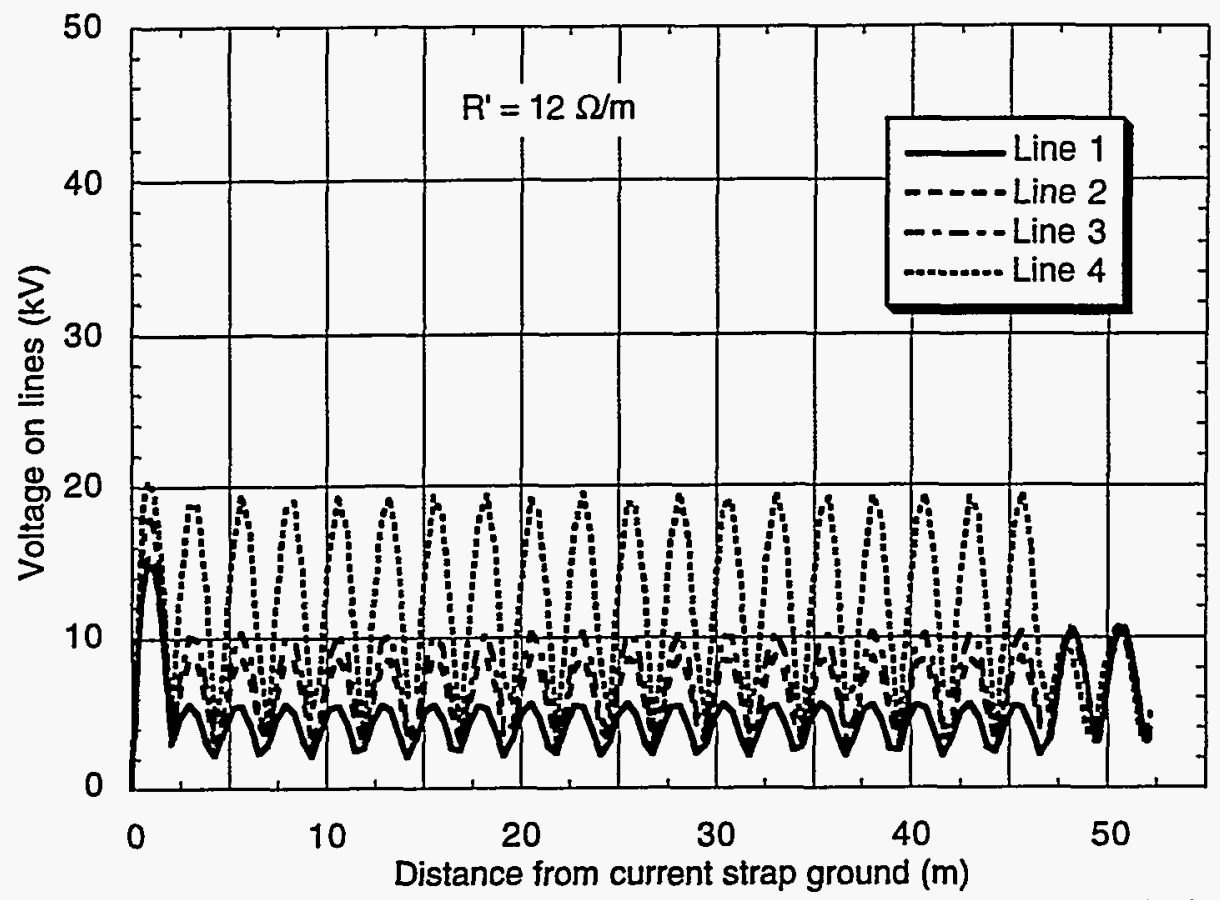

Fig. 13. Case 2. Voltage vs distance from strap ground on the four transmission lines for $\mathrm{R}^{\prime}=12 \Omega / \mathrm{m}$ at $60 \mathrm{MHz}$.

The main disadvantage of this configuration is that it is useful for only narrow-band operation without changing the location and/or length of the PMS. As the frequency departs from the resonant frequency, the strap-PMS circuit becomes nonresonant, and the VSWR in the region between the PMS and the T\&M equipment becomes very high, resulting in high dissipation in the lines in this region. Figure 14 shows the fraction of power to the plasma as a function of frequency for two values of effective losses in the resonant structure. For this calculation, the T\&M system was retuned to match at each frequency, except that the PMS length and location were kept fixed. While a value of $R^{\prime}=0.005 \Omega / \mathrm{m}$ appears reasonable for the large coax outside the antenna, a somewhat higher value may occur inside the antenna. The two curves bracket the probable range of values. If the lower value is obtained, then a band of $\pm 5 \mathrm{MHz}$ could be covered, with as much as $70 \%$ of the input power being delivered to the plasma. For the higher value of R', the equivalent frequency range would be about $\pm 2 \mathrm{MHz}$. 


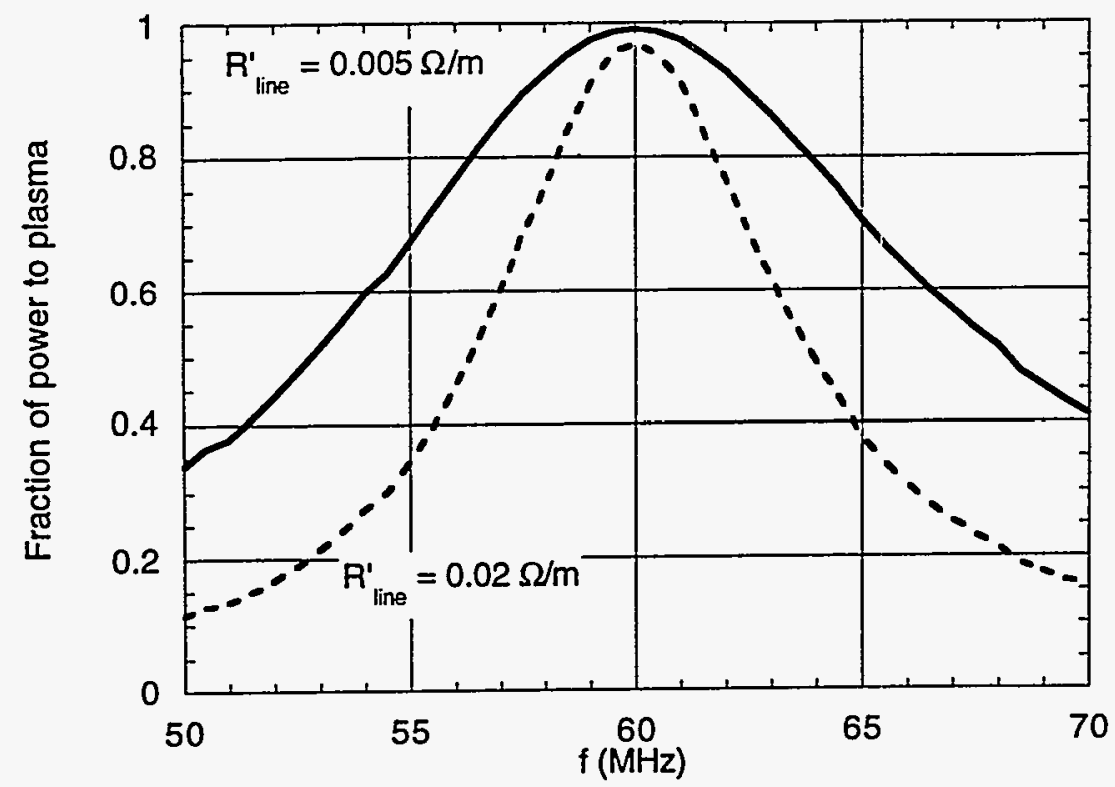

Fig. 14. Case 2. Fraction of power to the plasma vs frequency, for $R^{\prime}=3 \Omega / \mathrm{m}$.

\subsection{CASE 3 - CAPACITOR-TUNED CIRCUIT, DECOUPLERS FAR FROM ANTENNA}

A variation of Case 2 was studied to see if it would remedy the fixed-frequency nature of that configuration. For this case, a high-voltage vacuum capacitor, similar to those available commercially, was placed outside the ITER vacuum flange. The circuit is shown in Fig. 15. The length of the transmission line between the end of the current strap and the capacitor was chosen to be about $7.2 \mathrm{~m}$. This length allows the strap-transmission line-capacitor combination to be resonant at frequencies near 40,60 , and $80 \mathrm{MHz}$. In addition, because the capacitor can be tuned, a limited frequency range can be scanned in each of these bands. Figure 16 shows the three resonant frequency ranges as a function of capacitance value.

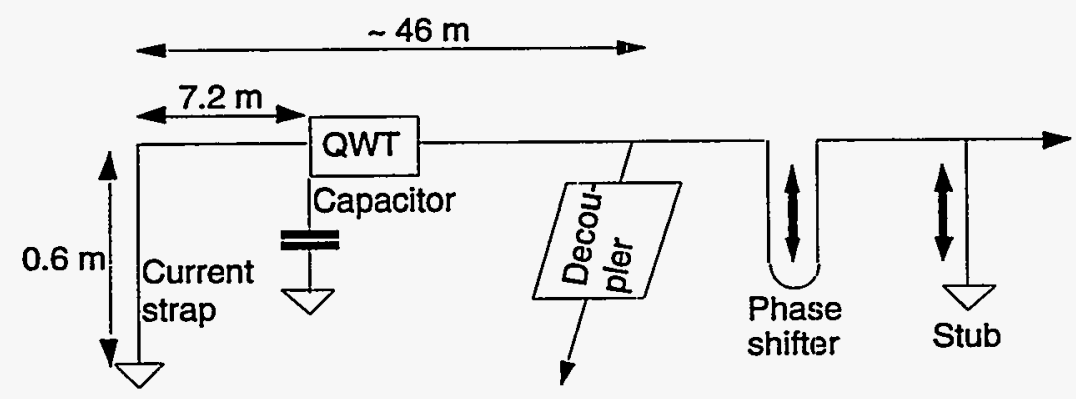

Fig. 15. Case 3. Schematic and dimensions.

QWT is a quarter-wave transformer at $60 \mathrm{MHz}$. 


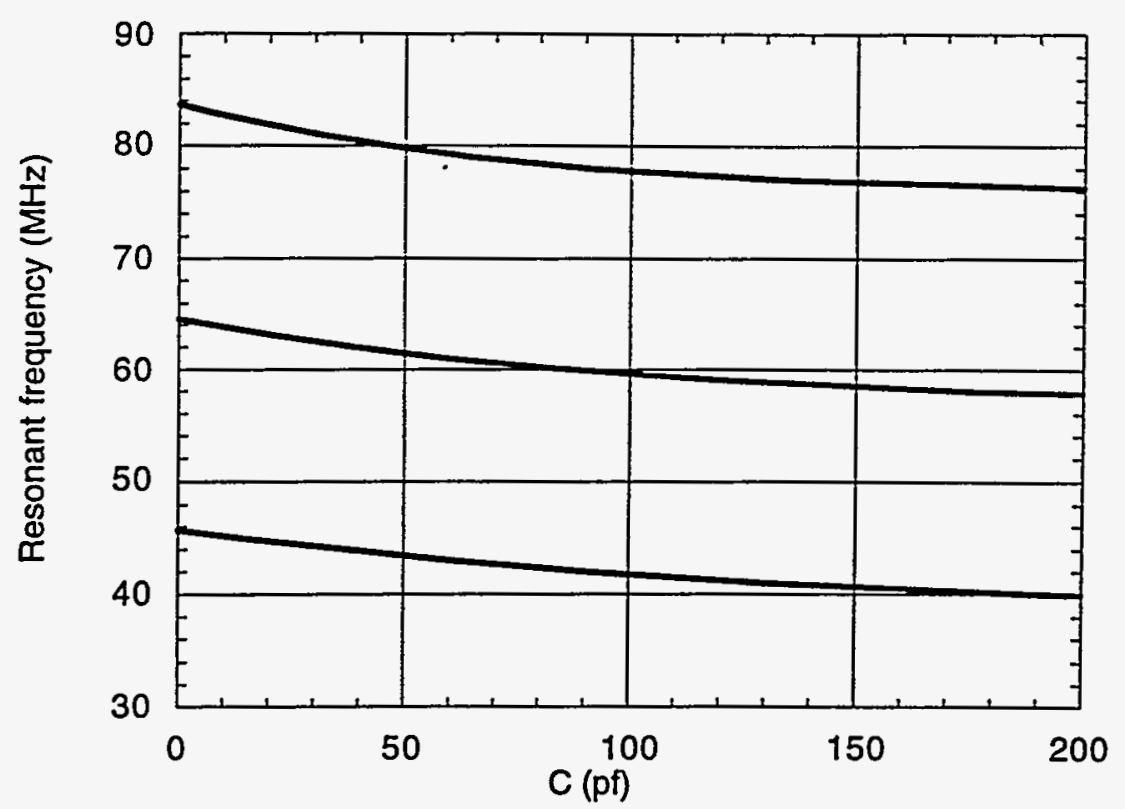

Fig. 16. Case 3. Frequency bands that can be tuned by variable capacitor.

For the transmission line lengths shown, the capacitance value required to resonate at $60 \mathrm{MHz}$ is $84 \mathrm{pf}$. If $\mathrm{R}^{\prime}=3 \Omega / \mathrm{m}$, the impedance seen looking into the resonant circuit is $\approx 800 \Omega$, which would cause a high VSWR if this were connected directly to a $30-\Omega$ feed line. A quarter-wave transformer (QWT, see Fig. 15) was added to the system on the generator side of the capacitor to lower the VSWR in the line between the decoupler and the capacitor. The QWT length was set at $1.25 \mathrm{~m}(\lambda / 4$ at $60 \mathrm{MHz})$, and the characteristic impedance of the line was set to $155 \Omega$, which will transform the 800- $\Omega$ impedance down to approximately $30 \Omega$.

Figure 17 shows voltage vs distance from strap ground for 60 and $64 \mathrm{MHz}$, with the capacitance value chosen to achieve resonance at each frequency. As can be seen, the match at $60 \mathrm{MHz}$ is very good as evidenced by the almost constant voltage on the generator side of the QWT. At $64 \mathrm{MHz}$, the VSWR is about 1.5. For this plot (as in the preceding cases), the power delivered to the plasma is $12.5 \mathrm{MW} /$ port with a plasma load of $3 \Omega / \mathrm{m}$. 


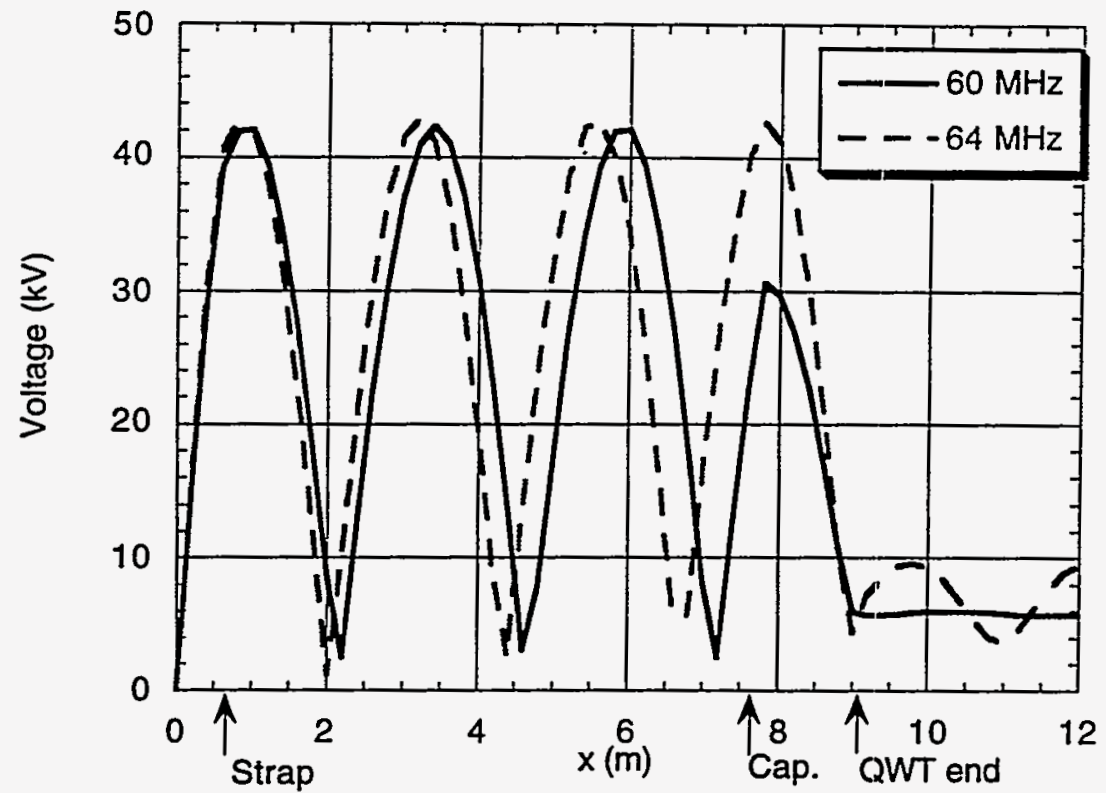

Fig. 17. Case 3. Voltage vs distance from strap ground for two frequencies in the 60-MHz tuning band. The QWT impedance is chosen for a perfect match at $60 \mathrm{MHz}$ and $\mathrm{R}^{\prime}=3 \Omega / \mathrm{m}$.

Figure 18 shows the same calculation for two frequencies in the $40-\mathrm{MHz}$ band. For these frequencies, the peak voltage needed to deliver $12.5 \mathrm{MW} /$ port is reduced from 42 to about $35 \mathrm{kV}$, assuming again a plasma load resistance of $3 \Omega / \mathrm{m}$. Surprisingly, the QWT helps match even at these frequencies. The peak voltage on the generator side of the QWT (i.e., between the QWT and the tuning equipment) is between 10 and $15 \mathrm{kV}$ for the curves shown. Similar results are obtained for the $80-\mathrm{MHz}$ band.

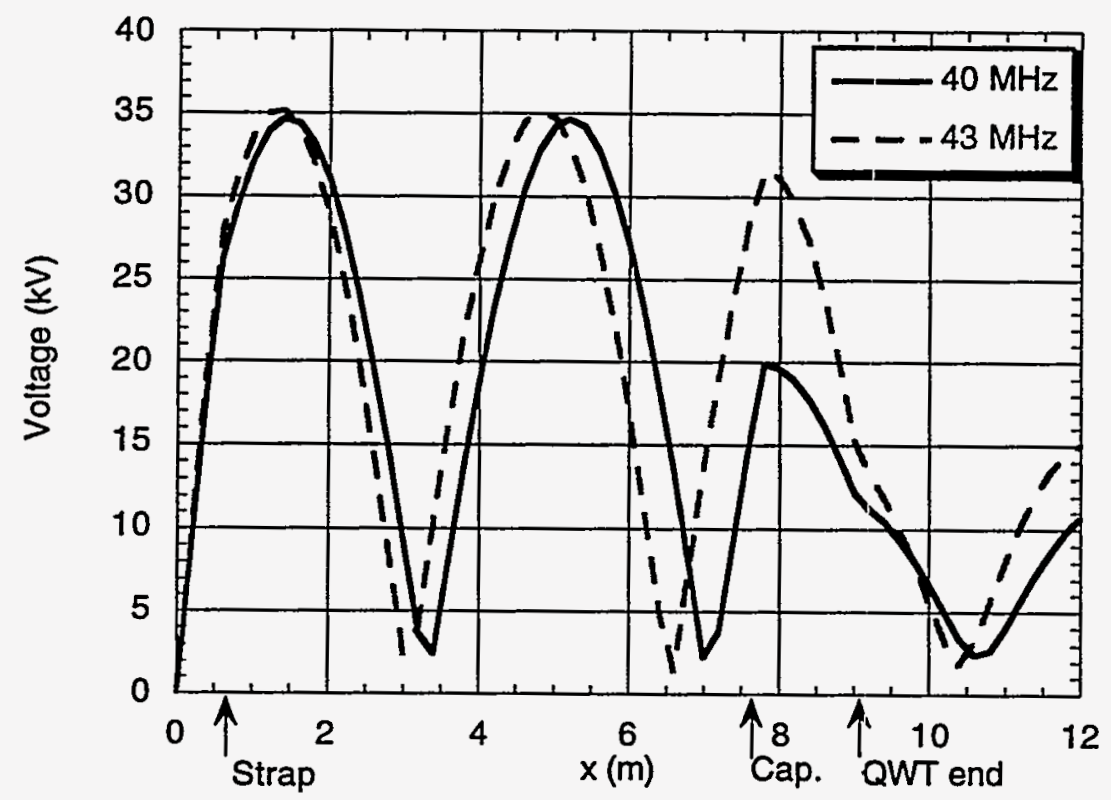

Fig. 18. Case 3. Voltage vs distance from strap ground for two frequencies in the $40-\mathrm{MHz}$ band. The QWT is the same as for the $60-\mathrm{MHHz}$ case. 
Do capacitors exist that will operate at the currents and voltages required of them in this type of operation? The answer is a qualified "yes." Figure 19 shows the capacitance values, the peak capacitor current, and the peak voltage on the capacitor vs frequency for both the $40-\mathrm{MHz}$ and $60-\mathrm{MHz}$ bands, assuming $\mathrm{R}^{\prime}=3 \Omega / \mathrm{m}$ and $12.5 \mathrm{MW}$ of power/port.
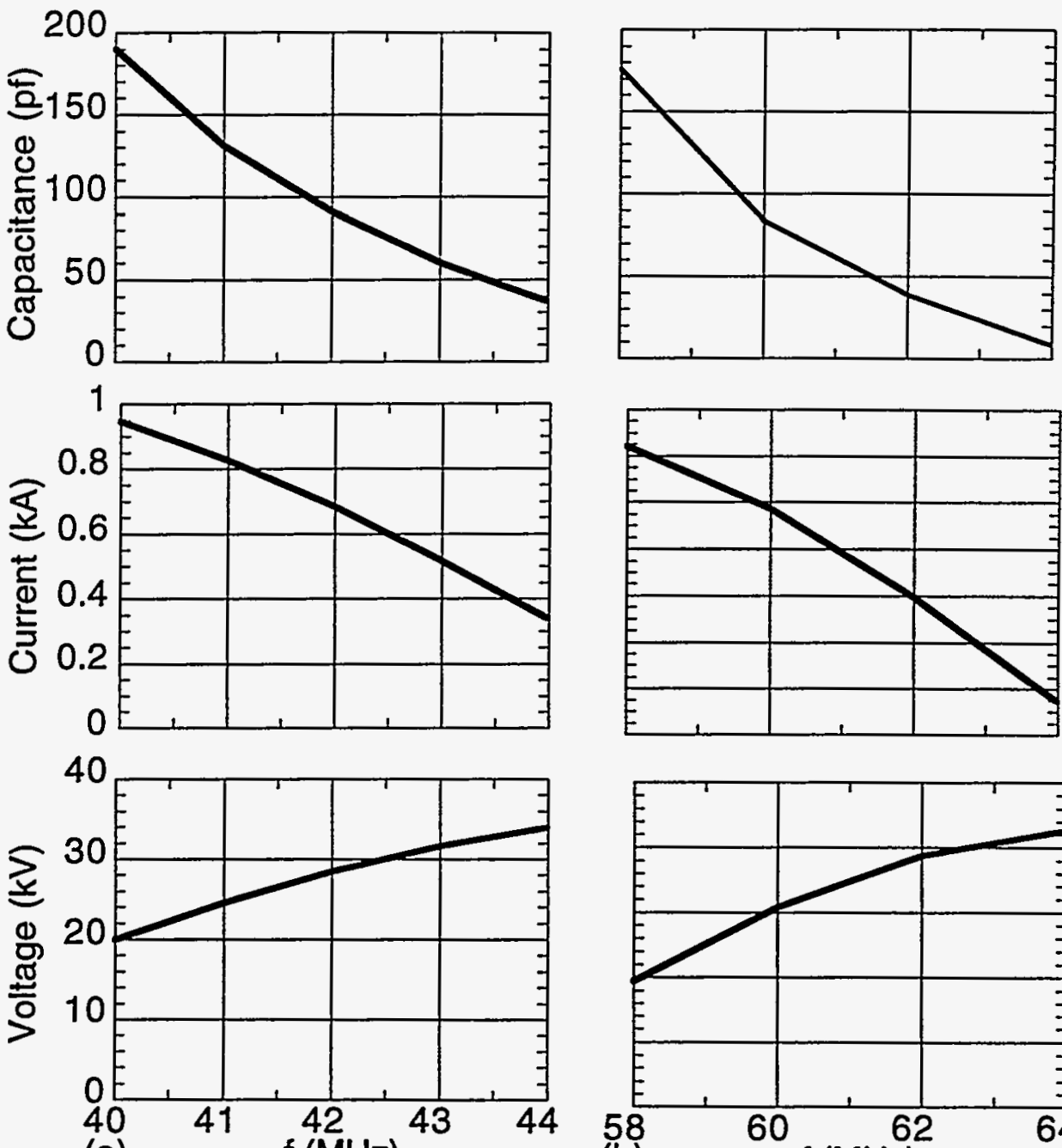

(a)

$\mathrm{f}(\mathrm{MHz})$

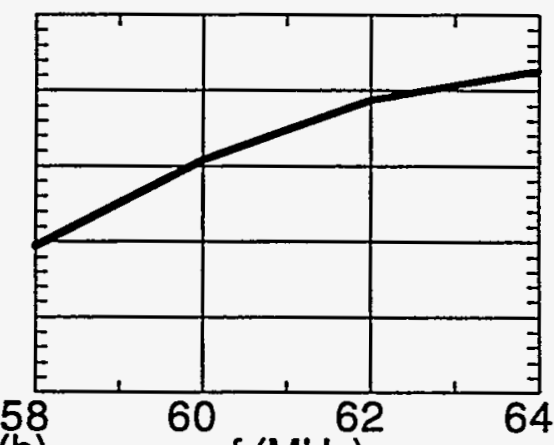

(b)

$f(\mathrm{MHz})$

Fig. 19. Case 3. Capacitance, peak current in the capacitor, and voltage on the capacitor vs frequency for (a) $40-\mathrm{MHz}$ band and (b) $60-\mathrm{MHz}$ band.

For the ranges shown, currents $\leq 1.2 \mathrm{kA}$ and voltages $\leq 45 \mathrm{kV}$ are needed. Water-cooled vacuum capacitors are commercially available with ratings in this range; for example, the Comet CV7W 300F/70 has a tuning range of 20 to $300 \mathrm{pf}$, a peak working voltage of 70 $\mathrm{kV}$, and a peak current capacity of $1.2 \mathrm{kA}$ (at $16 \mathrm{MHz}$ ). ${ }^{12}$ However, these capacitors have non-negligible internal inductance that must be considered when doing detailed design calculations. In addition, the current-carrying capacity is frequency-dependent and must be evaluated more carefully. Nevertheless, capacitors with properties similar to those required are available off-the-shelf.

Capacitors were used as the tuning elements in this analysis because they are compact and could be easily installed on the transmission line. A shorted stub tuner could be used just as well to add a reactance where the capacitor is located. This would result in a 
broader tuning band, since then both capacitive and inductive reactance could be added, resulting in a greater tuning range. The possible disadvantage would be that the stub would take up more room near the antenna.

\section{RESULTS: CONFIGURATIONS WITH FREQUENCY SHIFT}

Cases 1-3 have the decouplers at a distance of nearly $50 \mathrm{~m}$ from the antenna. Frequency-shift matching will not work with the decouplers at this location because frequency shifts of the order needed $(\geq 0.1 \mathrm{MHz}$ ) will cause significant admittance changes at the decoupler connection points and would require retuning of the decouplers.

In this section, we consider cases with the decouplers located at a high-voltage point near the antenna. The decoupler settings are relatively insensitive to modest changes in frequency because small frequency changes will cause only small admittance changes at the decoupler connection. Because they are connected at a high-voltage point, the settings of the decouplers are also independent of the interstrap phasing, which means that fast phase changes can be done during a shot. We examine several configurations in which small changes in the frequency (frequency-shift matching) are used to match the system when changes in plasma load occur. Case 4 has a frequency shift only. Case 5 uses both a frequency shift and a fast capacitor for fast matching.

\subsection{CASE 4 - PMS WITH DECOUPLERS NEAR ANTENNA, $\triangle$ F FOR MATCHING}

Figure 20 shows a schematic of the configuration. In this case, the decoupler is the closest matching element to the antenna and is connected to the transmission line a short distance outside the cryostat. The PMS is located a short distance from it. An additional phase shifter between the antenna and PMS has been added because of the extreme sensitivity of the circuit operation to the PMS locations. For coupled circuits, these distances must be individually adjusted (i.e., one decoupler-PIMS distance for all 4 coupled lines will not work); this will be discussed further below.

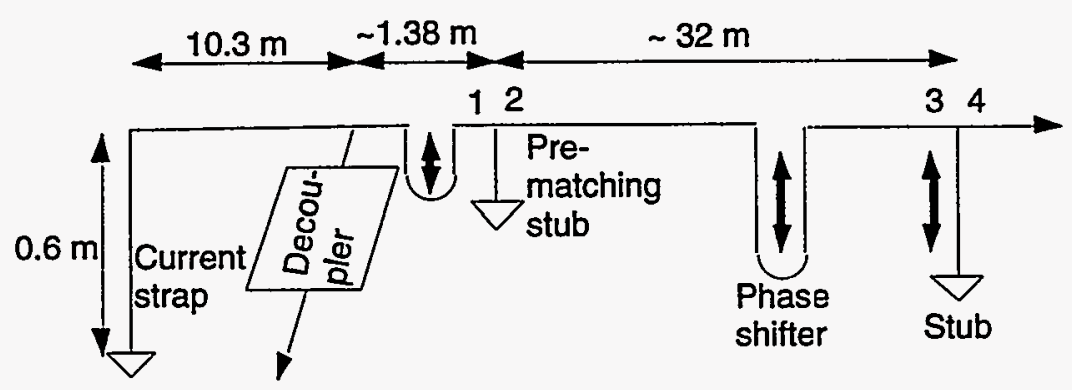

Fig. 20. Case 4. Schematic and dimensions.

A configuration similar to this (but without the decouplers) has been used for frequency-shift matching by Wade et al. on JET. ${ }^{13}$ It has recently been analyzed in more detail by Lamalle, ${ }^{14}$ again for use on JET, but without the inclusion of the coupling between current straps. Our calculations include the results of coupling and add some new information. 


\subsubsection{Results for an uncoupled system}

Figure 21 indicates the behavior of the circuit for the comparatively simple case of a single current strap, with interstrap coupling neglected. The frequency and the line lengths were chosen to represent a typical ITER layout as shown in Fig. 20. The plots are admittance Smith charts of the system response during a resistance scan of $3 \leq R^{\prime} \leq 20$ $\Omega / \mathrm{m}$. Figure 21(a) shows the behavior for constant frequency, while Fig. 21(b) shows the corresponding response when the frequency is shifted to optimize the coupling. The curve labels correspond to the similarly labeled observation points indicated in Fig. 20.

As is shown in Fig. 21(a), the location of the PMS is chosen so that the load line (1) is approximately tangent to a $\operatorname{Re}(\mathrm{Y})=$ constant circle. The reactance of the PMS is chosen to rotate the load line to position (2), at which the two ends of the load line are at the same value of $|\rho|$. The distance to the main matching stub is chosen to move the load line to position 3, at which some point on the load line is on the $\operatorname{Re}(\mathrm{Y})=\mathrm{Y}_{\text {line }}$ curve $\left(\mathrm{Y}_{\text {line }}=1 / 30\right.$ mho, the line admittance). Finally, enough reactance is added by the main stub to move the load line to position (4), where the line is exactly matched at one value of $R^{\prime}$.
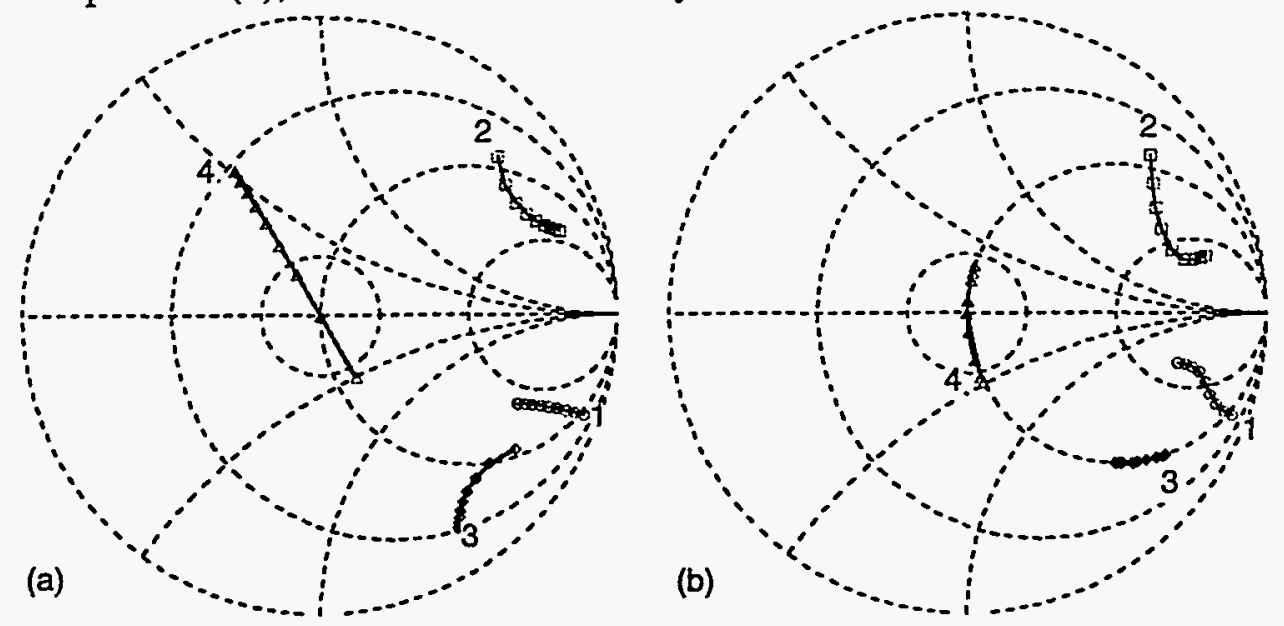

Fig. 21. Case 4, uncoupled. Smith chart plots of admittance seen looking toward the antenna from locations 1-4 (shown in Fig. 20) during a change in R', for (a) constant frequency and with (b) calculated optimum frequency shift.

The addition of a frequency shift changes the situation as shown in the Fig. 21(b). The frequency shift has been chosen to make $\operatorname{Re}(\mathrm{Y})=\mathrm{Y}_{\text {line }}$ for all of curve 3 . Because of the choice of the location of curve 2, curve 3 is folded on itself, so that the addition of the main stub to move the load line from (3) to (4) puts almost all of the load line inside the VSWR $=1.5$ circle (the small circle at the center of the plots). Figure 22 shows the calculated frequency shift and the magnitudes of $\rho$ at locations $1-4$. As can be seen, $|\rho| \leq$ 0.2 (i.e., VSWR $\leq 1.5$ ) for $R^{t}=3$ to $17 \Omega / \mathrm{m}$. 

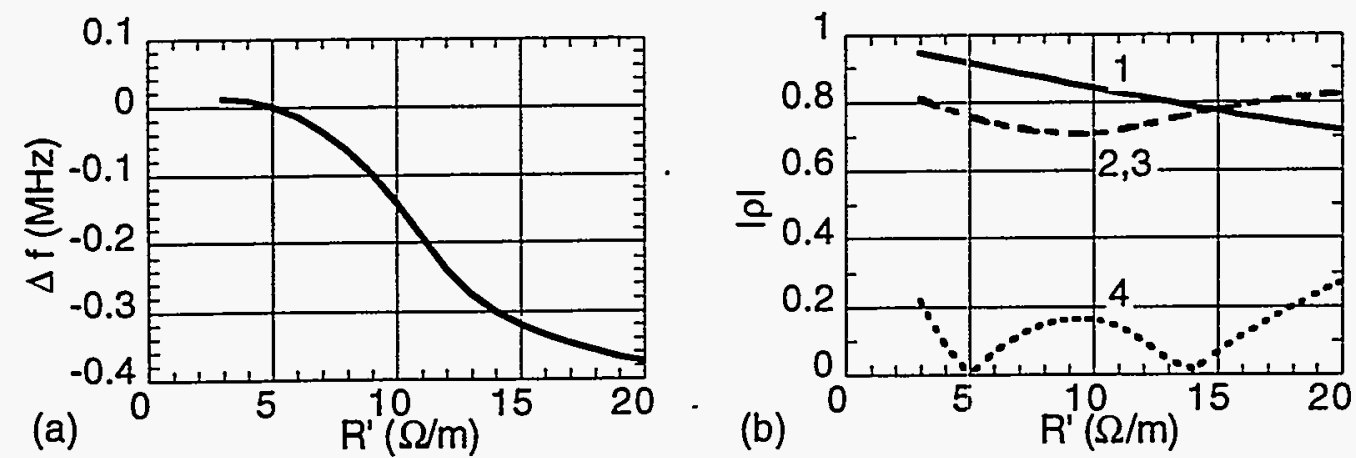

Fig. 22. Case 4, uncoupled. (a) Calculated frequency shift and (b) $|\rho|$ vs $R^{\prime}$

Figure 23 shows the maximum voltage in different sections of the T\&M system as a function of $\mathrm{R}^{\prime}$, when operated with frequency-shift matching using the same circuit parameters as in Figs. 21 and 22, for 12.5 MW of power to the plasma from each port. Although the maximum voltage on the antenna side of the PMS is $>40 \mathrm{kV}$ at the lowest values of $R^{\prime}$, the generator side of the PMS shows maximum voltages of about $20 \mathrm{kV}$. Thus, the high-voltage region can be confined to the region on the antenna side of the PMS.

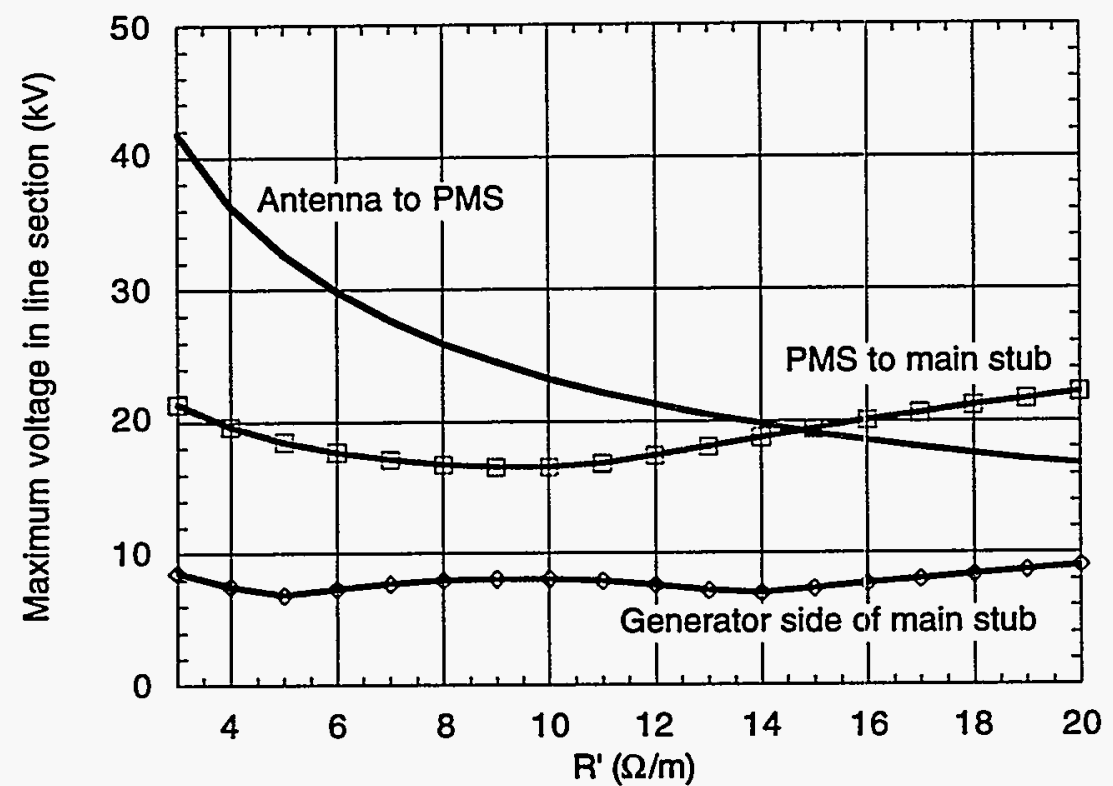

Fig. 23. Case 4, uncoupled. Maximum voltage in different line segments vs $\mathrm{R}^{\prime}$

Several points should be made regarding this system:

1. Satisfactory behavior depends critically on the location of the PMS. Changes of 1 or $2 \mathrm{~cm}$ can make the difference between the system working or not.

2. For a given PMS position, two solutions are possible for the length of the PMS, but only one appears to give a well-behaved $\Delta f$ vs $R^{\prime}$ curve. If the wrong solution is chosen, discontinuous changes in frequency may be needed to maintain a match as $\mathrm{R}^{\prime}$ increases. 
3. In the "ideal" analysis of this method, it is often assumed that the distance between the PMS and the main tuning stub is much larger than the distance from the PMS to the antenna ground. This has the beneficial effect that the frequency shift will not significantly change the load lines at positions 1 and 2 . As can be seen by comparing the (a) and (b) plots in Fig. 21, this is not a very good approximation in this case, since curve (1) is altered significantly by the frequency shift.

4. Even though $|\rho|$ between the PMS and main stub is in the range of 0.7 to 0.8 (corresponding to a VSWR of about 6 to 9), the voltages in this part of the line are not particularly high ( $\leq 20 \mathrm{kV}$, compared to a high $>40 \mathrm{kV}$ between the antenna and the PMS for $12.5 \mathrm{MW}$ to the plasma at $\mathrm{R}^{\prime}=3 \Omega / \mathrm{m}$ ).

5. Losses in this system are modest; the fraction of power to the plasma is $\geq 94 \%$ even at $R^{\prime}=3 \Omega / m$.

6. A trade-off can be made in the selection of the location of the PMS; a smaller frequency shift can be used to match than that shown in Fig. 22, for example, if one is willing to accept a higher value of $\rho$ (and higher voltages and losses) in the line between the PMS and the main stub.

\subsubsection{Results for a coupled system}

The coupled system is more difficult computationally to evaluate than the uncoupled system, and work has only started in optimizing this case. The results we present here are an existence proof, because a solution has been found that has reasonably good properties. However, it is far from an optimized solution.

Coupling considerably complicates the choice of the PMS position. For $\pi / 2$ phasing between straps, XPMS (the decoupler-PMS distance) had to be set individually for each of the four lines. Results presented below have XPMS $=1.33 \mathrm{~m}, 1.385 \mathrm{~m}, 1.385 \mathrm{~m}, 1.33 \mathrm{~m}$, for the four coupled lines respectively. While this choice did not provide identical responses of the lines to changes in $R^{\prime}$ and $\Delta f$, they were reasonably similar. Figure 24 shows the frequency shift and the value of $\mid \mathrm{pl}$ averaged over all four lines as a function of $\mathrm{R}^{\prime}$, obtained using the FDAC code with $\pi / 2$ phasing between straps.
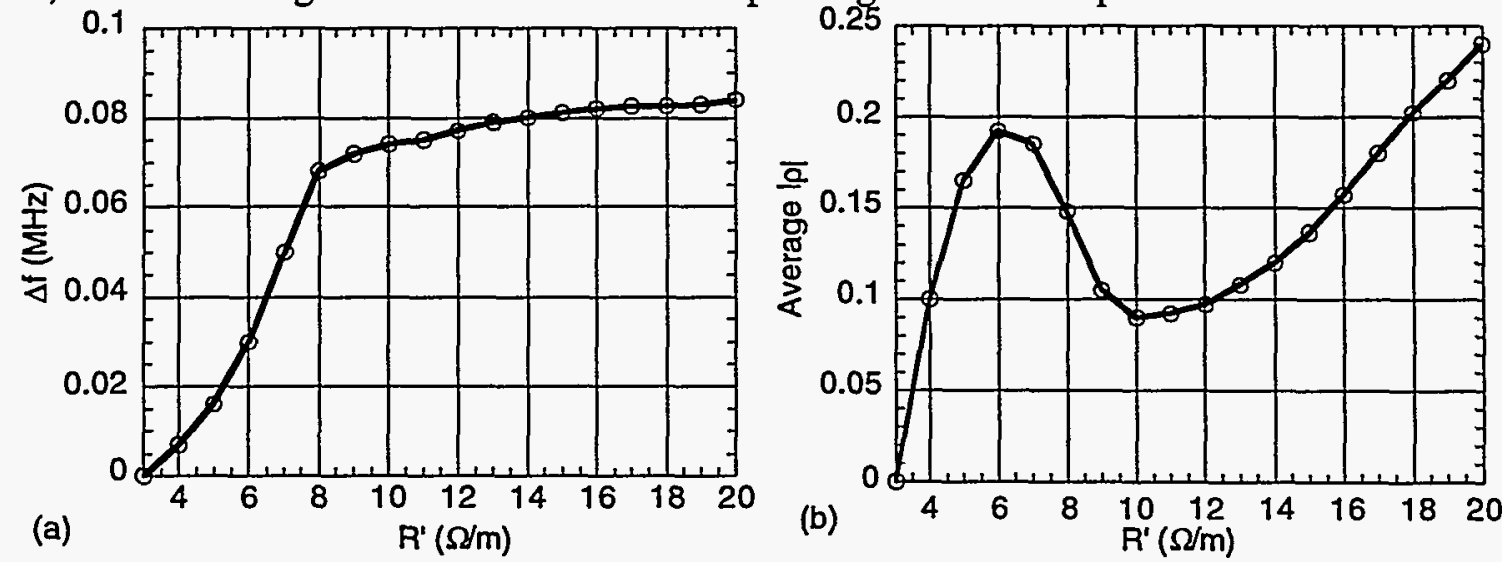

Fig. 24. Case 4, coupled. (a) Calculated frequency shift and (b)lpl at point 4 vs $R^{\prime}$ with coupled straps. 
Details of the behavior of each of the four lines are given in Fig 25, in which $|\rho|$ vs $f$ is plotted for each line for four different values of $\mathrm{R}$ '.
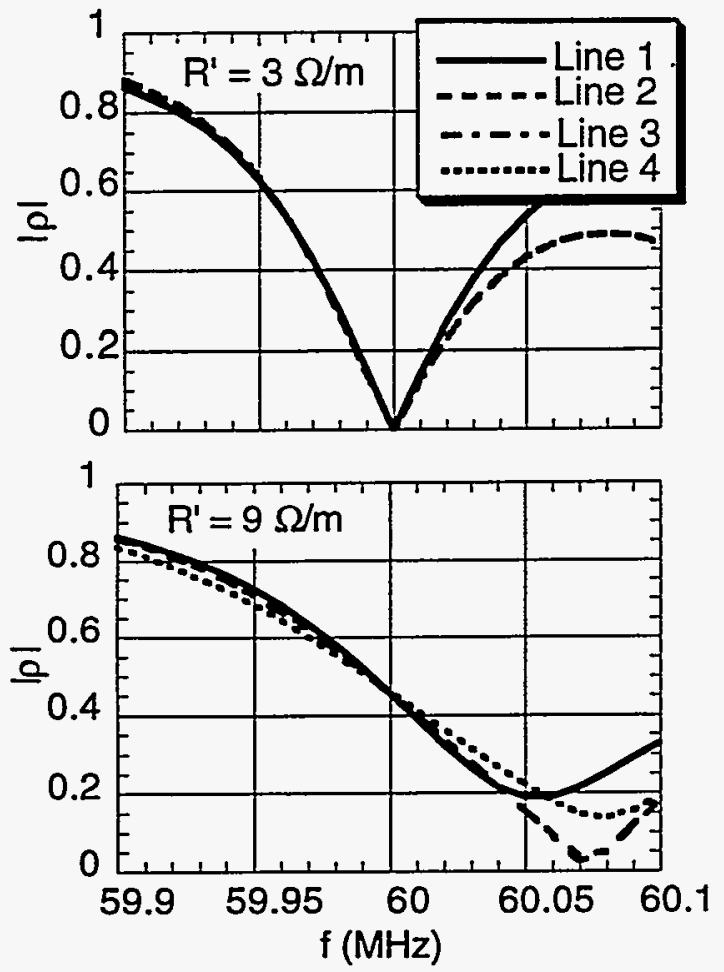
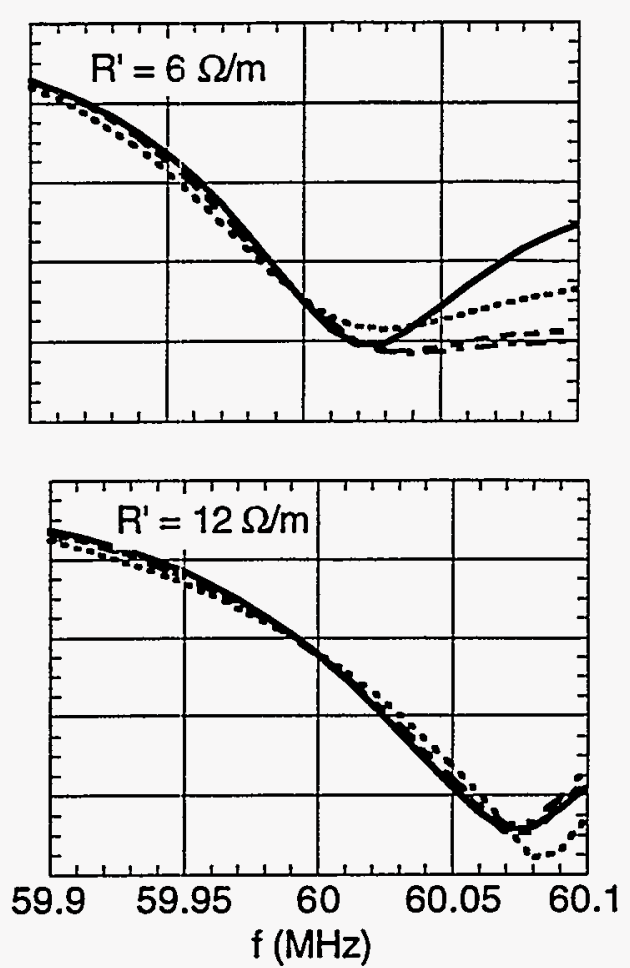

Fig. 25. Case 4, coupled. Ipl vs for each of the 4 coupled lines, for $\mathrm{R}^{\prime}=3,6,9$, and $12 \Omega / \mathrm{m}$.

We attempted to find a solution that would allow frequency-shift matching with XPMS the same for all four straps, but the behavior of the inner straps was qualitatively different from the outer because of the interstrap coupling when the lengths were equal; in one set, $\rho$ in the lines would increase for $\Delta \mathrm{f}>0$, for example, while $\rho$ would decrease in the other set.

In addition, operation at different phasing was not possible without changing the PMS positions. The phase could be changed from $+\pi / 2$ to $-\pi / 2$ with no problem, but we found that operation at 0 or $\pi$ phasing with the same values of XPMS as for $\pi / 2$ phasing would result in very high VSWR in some of the lines.

The results of this section indicate that a hybrid splitter and/or a fast variable capacitor is not required to maintain a relatively low VSWR at the generator; a frequency shift only will work to maintain the VSWR within an acceptable range over about a factor of 4 in $R$ '. The penalties follow:

1. The decoupler/ PMS must be located near, but outside of, the antenna.

2. The decoupler/PMS separation must be changed to operate effectively at different frequencies.

3. Tuning and operation appear critically sensitive on small changes in component values, particularly for the more realistic case with interstrap coupling included. 


\subsection{CASE 5 - PMS WITH DECOUPLERS NEAR ANTENNA, $\triangle \mathrm{F}$ AND $\Delta \mathrm{C}$ FOR MATCHING}

The final case utilized the configuration of the preceding case, with the addition of a fast capacitor in parallel with the final matching stub, as shown in Fig. 26. In this case, both frequency shifting and small changes in the capacitor value were used to match changes in $R^{\prime}$. The system was initially set up to provide a perfect match at $R^{\prime}=6.4 \Omega / \mathrm{m}$, with capacitance values of $\approx 120 \mathrm{pf}$. Then as $\mathrm{R}^{\prime}$ was varied, both the frequency shift $\Delta f$ and the capacitance value were varied to minimize the VSWR on the generator side of the T\&M system. The results are shown in Fig. 27.

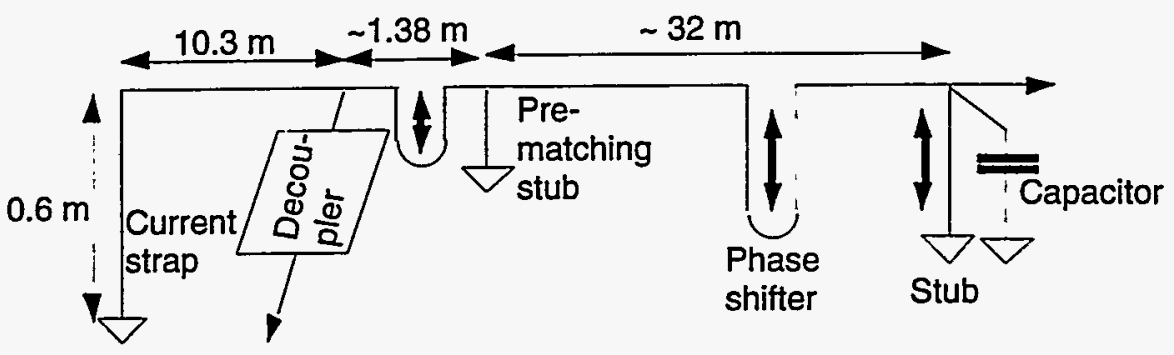

Fig. 26. Case 5. Schematic and dimensions.
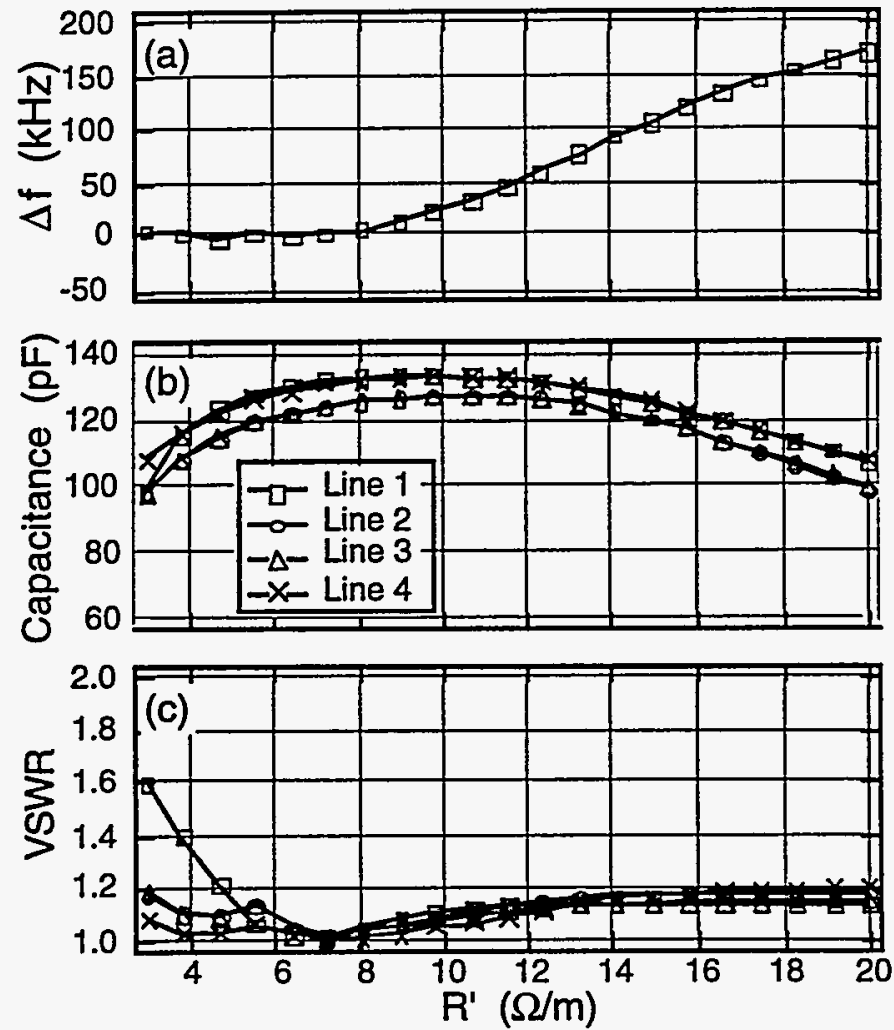

Fig. 27. Case 5. (a) Frequency shift for all lines, (b) capacitance values, and (c) VSWRs vs $R^{\prime}$. System was matched at $R^{\prime}=6.4 \Omega / \mathrm{m}$.

The top curve shows the frequency shift, which varies from 0 to $\approx 160 \mathrm{kHz}$. The center curve shows the capacitance values of the four capacitors in the four lines, and the bottom curve shows the resulting VSWRs. This system is seen to work very effectively. The 
VSWR for high values of R' never exceeds 1.2 , and for the lowest value of $3 \Omega / \mathrm{m}$ it only goes to 1.6 in the worst line.

The addition of the fast capacitor provides a significant advantage over the performance of case 4 . The capacitive change $\Delta \mathrm{C}$ required is only $\approx 30 \mathrm{pf}$ for the case shown, although changes of up to $\pm 50 \mathrm{pf}$ have been needed in some cases. $R \& D$ is needed to determine the time response of the capacitor tuning that can be achieved.

\section{RESULTS: SIMULATION OF ELMS IN ITER}

The behavior of ELMs has been studied in DIII-D, and the characteristic changes in plasma loading have been measured on the DIII-D ion cyclotron heating (ICH) antennas in an ELMy H-mode discharge. ${ }^{15}$ The results of the measurements are shown in Fig. 28. R' varies between 3 and $20 \Omega / \mathrm{m}$.

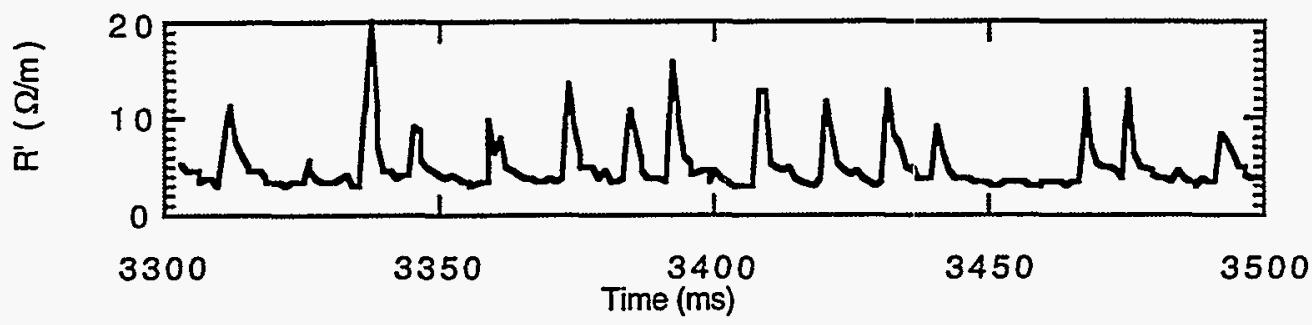

Fig. 28. Behavior of $R^{\prime}(t)$ measured on DIII-D during an ELMy H-mode discharge.

This time-behavior was used as input to the ITER T\&M system configuration that was simulated as case 4 previously. The system was modeled. with a hybrid splitter passive ELM dump, and the power that was delivered to the plasma as a function of time was calculated both with and without the use of frequency-shift matching. The system was matched for $R^{\prime}=6.3 \Omega / \mathrm{m}$, so the match was not perfect for the lowest values of R'. However, this choice gave good results for the total performance of the system.

Results are shown in Fig. 29. Curve A shows the calculated frequency shift $(\Delta f)$ vs time. Curve B shows the VSWR in the line between the main tuning stub and the hybrid splitter, and curve $C$ shows the VSWR on the generator side of the hybrid splitter. Curve D shows the power delivered to the plasma.

For these simulations, the average power delivered to the plasma is $\approx 90 \%$ of the input power. The addition of the frequency shift maintains a better match during the very high transients in $R^{\prime}$ but makes only about a $1 \%$ improvement in the average power delivered to the plasma, because the high values of $R^{\prime}$ are rare and of short duration. As can be seen, the VSWR on the generator side of the hybrid splitter is always maintained at a low value. 

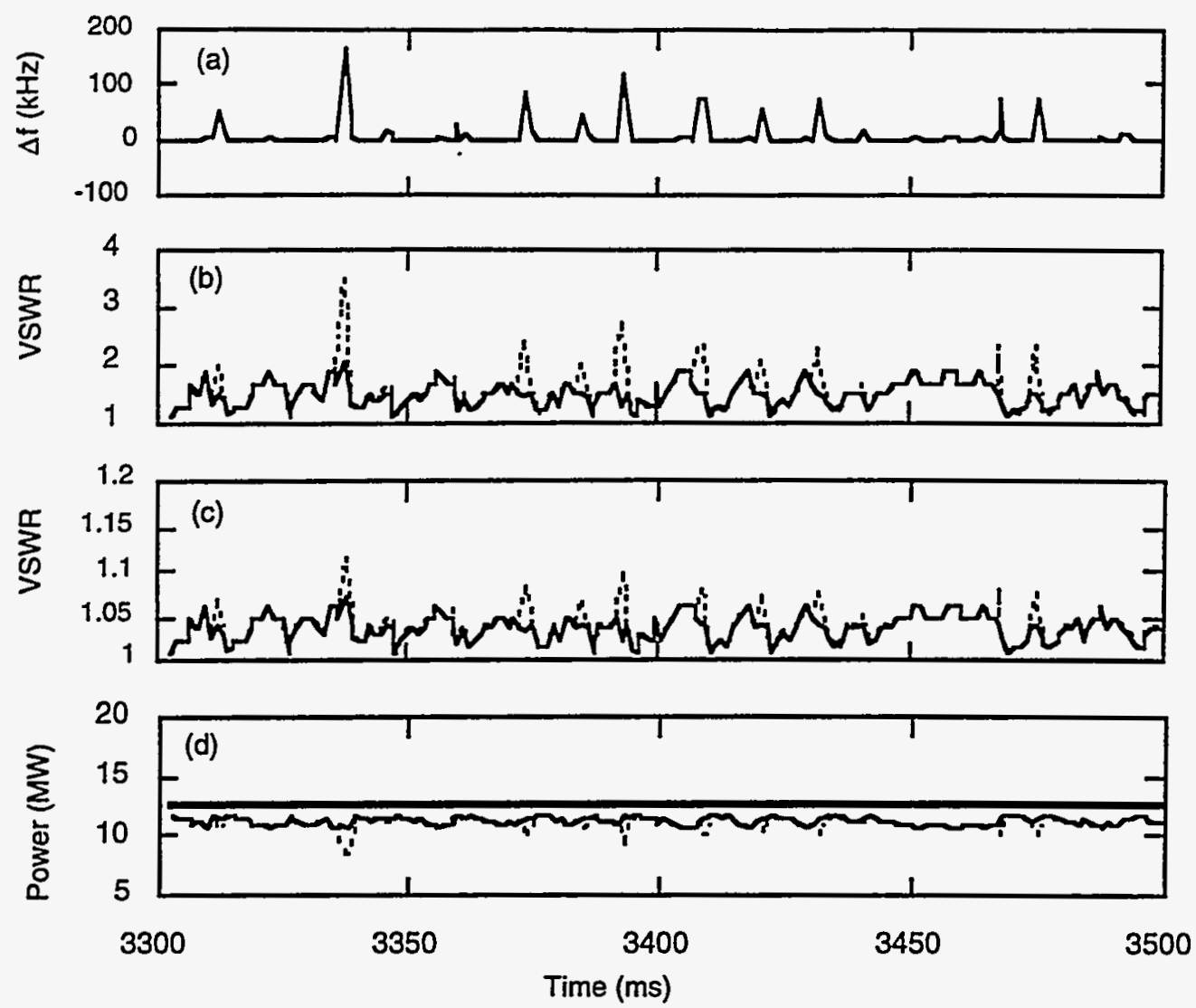

Fig. 29. Response of the case 4 T\&M system to the R' fluctuation of Fig. 28.

Solid lines are with frequency-shift matching, dashed lines with no frequency shift.

(a) calculated frequency shift,

(b) VSWR in the line between the main tuning stub and the hybrid splitter,

(c) VSWR on the generator side of the hybrid splitter, and

(d) power delivered to the plasma.

\section{RECOMMENDATION FOR R\&D TASKS}

\section{Testing of passive system on a tokamak}

The passive ELM dump circuitry using a hybrid splitter appears very promising from the standpoint of passive protection against ELM-generated reflected power. Results from the DIII-D measurements indicate that this could be very useful in maintaining a high overall power level while not requiring fast-response, feedback-controlled circuitry. This should be experimentally tested on one or more high-power IC systems in the near term to demonstrate its utility .

\section{Testing of frequency-shift matching on a tokamak}

The results given in case 4 are encouraging. A test of frequency-shift matching on an $\mathrm{rf}$ system that is operating on a real tokamak in the presence of $\mathrm{L}-\mathrm{H}$ transitions and ELMs is needed to demonstrate the practical utility of this technique. 


\section{Testing of fast capacitive system on a tokamak}

The use of fast capacitors in the T\&M system appears feasible also, based on the results shown in case 5 . A system using fast capacitive matching in conjunction with frequency shift could provide matching in times of $\approx 10 \mathrm{~ms}$, which would probably be fast enough . Further modeling of T\&M circuits using this concept should be continued, and tests of this concept should be carried out on an experiment.

\section{Testing of improved arc discrimination systems}

In order to utilize some of the ELM-protection methods modeled, we must be sure that when a change in the plasma load resistance is seen that it is really from the plasma, and is not caused by an if arc in the antenna or T\&M system. If it is from the plasma, then the T\&M system can respond appropriately, rematch in a short time, and continue the delivery of high if power to the plasma. However, if an arc is mistaken for a change in the plasma loading, the T\&M system will respond and continue to couple power into the arc, probably resulting in permanent damage to the if component where the arc is taking place.

For this reason, foolproof techniques must be developed to discriminate between the increases in reflected power caused by plasma changes and those caused by breakdown in the if system. This development must occur simultaneously, if not before, the testing of the fast T\&M systems just described. Development and testing of arc-discrimination and protection circuitry must be carried out. There is considerable work underway in the international community, and it should be encouraged and maintained. 


\section{REFERENCES}

P.-H. Rebut letter to C. C. Baker, ORNL ITER Document S A0 LS 22 94-03-30 F; Annex 1 describing Task No. G 51 TD 03, "Design of Fast Tuning Elements for ICH System."

R. H. Goulding, et al., "Global ICRF system designs for ITER and TPX", Proc. 11th Top. Conf. on Radio Frequency Power in Plasmas, p. 397 (AIP Conference Proc. 355, 1996).

PV-WAVE is a program by Visual Numerics, Inc., Houston Texas.

S. Ramo, J. R. Whinnery, T. van Duzer, Fields and Waves in Communication Electronics, (Wiley, New York, 1984).

D. W. Swain et al.,'TTER In-port Antenna Design Study - Interim Report for ITER Task D89," submitted to the JCT at the January 1995 In-port antenna design meeting.

P. M. Ryan et al., "Methods of calculating selected geometrical effects in the design of ICRH antennas," Fusion Eng. and Design 24, 135 (1994).

V. P. Bhatnagar, private communication; D. B. Batchelor, private communication. See V. P. Bhatnagar et al., "A 3-D analysis of the coupling characteristics of ion cyclotron resonance heating antennae," Nucl. Fusion 22, 280 (1982); and I. P. Pavlov and J. A. Heikkinen, "Effect of antenna orientation and plasma anisotropy on the directivity of fast wave antenna radiation," Phys. Plasmas 2, 3573 (1995) and references therein for a more general discussion of poloidal anisotropy effects.

M. D. Carter et al., Nucl.Fusion. 36, 209 (1996).

D. W. Swain, F. W. Baity, D. B. Batchelor et al., Bull. Am. Phys. Soc. 39, 1649 (1994).

G. Bosia (ITER JCT, Garching), private communication to D. Swain.

D. W. Swain et al., "Preliminary Design of In-Port Ion Cyclotron Radio Frequency Antenna - Final Report for ITER Design Task D5," ITER Report ITER/US/95/TVRF-04, submitted to the ITER JCT in May 1995.

Vacuum Capacitor Catalog of Comet, Ltd., Berne, Switzerland; and private communication from Lance Scott, Comet North America, Inc.

T. J. Wade et al., "Automatic power coupling to any plasma in JET," Proc. 12th Symp. Fusion Engineering, p. 1200 (1987). See also T. J. Wade et al., "Development of the JET ICRH plant," Fusion Eng. and Design 24, 123 (1994), and references therein.

P. Lamalle (JET Joint Undertaking), private communication.

R. H. Goulding et al., "Design of feed networks for ICRF arrays," Bull. Am. Phys. Soc. 40, 1705 (1995). 
$\checkmark$

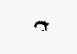

$=$ 
ORNL/TM-13230

Dist. Category UC-420

\section{INTERNAL DISTRIBUTION}

1. F. W. Baity

2. D. B. Batchelor

3. G. L. Bell

4. B. A. Carreras

5. M. D. Carter

6. R. H. Goulding

7. D. J. Hoffman

8. S. L. Milora

9. P. M. Ryan

10-13. D. W. Swain
14. N. A. Uckan

15-16. Laboratory Records Department - RC

17. Laboratory Records Department

18. Central Research Library

19. Document Reference Section

20. Fusion Energy Division Library

21. Engineering Technology/Fusion Energy Division Publications Office

22. ORNL Patent Section

\section{EXTERNAL DISTRIBUTION}

23. Office of the Assistant Manager for Energy Research and Development, Department of Energy Field Office, Oak Ridge, P.O. Box 2000, Oak Ridge, TN 37831

24. C. C. Baker, U.S. ITER Project Office, Univ. of California, San Diego, 9500 Gilman Drive, Bldg. 302, La. Jolla, CA 92093-0035

25. V. Bhatnagar, JET Joint Undertaking, Abingdon, Oxfordshire, OX 14 EA, United Kingdom

26. G. Bosia, ITER c/o Max-Planck Institut für Plasmaphysik, Boltzmannstr. 2, D-85748 Garching bei München, Germany

27. J. D. Callen, Department of Nuclear Engineering, University of Wisconsin, Madison, WI 53706-1687

28. R. Callis, General Atomics, Fusion Group 13/265, P. O. Box 85608, San Diego, CA 92186-9784

29. R. W. Conn, Mechanical, Aerospace, and Nuclear Engineering Department, 6291 Boelter Hall, University of California, Los Angeles, CA 90024-1597

30. N. A. Davies, Director, Office of Fusion Energy, Office of Energy Research, ER-50 Germantown, Department of Energy, Washington, DC 20585

31. F. Durodie, Ecole Royale Militaire, 30, Avenue de la Renaissance, B-1000, Brussels, Belgium

32. D. D'Ippolito, Lodestar Research Corporation, 2400 Central Avenue, P-5, Boulder, CO 80301

33. F. Engelmann, Max-Planck Institut für Plasmaphysik, Boltzmannstr. 2, D85748 Garching bei München, Germany

34. R. Freeman, General Atomics, Fusion Group, P. O. Box 85608, 13-269, San Diego, CA 92186-9784

35. T. V. George, Office of Fusion Energy Sciences, Office of Energy Research, ER-531 19901 Germantown Road, Germantown, MD 20874

36. C. Gormezano, JET Joint Undertaking, Abingdon, Oxfordshire, OX 14 EA, United Kingdom

37. R. J. Hawryluk, Princeton Plasma Physics Laboratory, P.O. Box 451, Princeton, NJ 08543 
38. J. C. Hosea, Princeton Plasma Physics Laboratory, P.O. Box 451, Princeton, NJ 08543

39. J. Jacquinot, JET Joint Undertaking, Abingdon, Oxfordshire OX14, 3EA, United Kingdom

40. H. Kimura, Japanese Atomic Energy Research Institute, Naka-machi, Nakagun, Ibaraki-ken 311-01, Japan

41. R. Koch, Institut für Plasmaphysik, Forschungszentrum Jülich GmbH KFA, Postfach 1913, D-52425 Jülich, Germany

42. D. M. Meade, Princeton Plasma Physics Laboratory, P.O. Box 451, Princeton, NJ 08543

42. W. Nevins, Lawrence Livermore National Laboratory, P. O. Box 808 (L-644), Livermore, CA 94551-9900

44. J.-M. Noterdaeme, Max-Planck Institute for Plasmaphysics, D-85748, Garching, Germany

45. E. Oktay, Office of Fusion Energy Sciences, Office of Energy Research, ER-55, 19901 Germantown Road, Germantown, MD 20874

46. R. Parker, ITER c/o Max-Planck Institut für Plasmaphysik, Boltzmannstr. 2, D-85748 Garching bei München, Germany

47. F. W. Perkins, ITER Co-center, 11025 North Torrey Pines Road, La Jolla, CA 92037

48. R. Pinsker, Genral Atomics, P. O. Box 85608, 13/254, San Diego, CA 92186-9784

49. M. Porkolab, Massachusetts Institute of Technology, 167 Albany St., Bldg. NW16-288, Cambridge, MA 02139

50. R. Prater, Genral Atomics, P. O. Box 85608, 13/268, San Diego, CA 921869784

51. D. Remsen, General Atomics, P. O. Box 85608, San Diego, CA 92186-9784

52. M. Roberts, Office of Fusion Energy Sciences, Office of Energy Research, ER-52, 19901 Germantown Road, Germantown, MD 20874

53. W. M. Stacey, School of Nuclear Engineering and Health Physics, Georgia Institute of Technology, Atlanta, GA 30332

54. H. S. Staten, Office of Fusion Energy Sciences, Office of Energy Research, ER-55 19901 Germantown Road, Germantown, MD 20874

55. Y.Takase, Massachusetts Institute of Technology, 167 Albany St., Bldg. NW16-122, Cambridge, MA 02139

56. K. I. Thomassen, Lawrence Livermore National Laboratory, P.O. Box 5511, Livermore, CA 94550

57. P. Vandenplas, Ecole Royale Militaire, 30, Avenue de la Renaissance, B-1000, Brussels, Belgium

58. T. Wade, JET Joint Undertaking, Abingdon, Oxfordshire OX14, 3EA, United Kingdom

59. F. Wesner, Max-Planck Institute for Plasmaphysics, D-85748, Garching, Germany

60. K. L. Wilson, Sandia National Laboratories, P. O. Box 969, Livermore, CA 94551-0969

61. J. R. Wilson, Princeton Plasma Physics Laboratory, P. O. Box 451, Princeton, NJ 08543

62. Bibliothek, Max-Planck Institut für Plasmaphysik, Boltzmannstrasse 2, D-85748 Garching, Germany

63. Bibliothek, Institut für Plasmaphysik, KFA Jülich $\mathrm{GmbH}$, Postfach 1913, D-5170 Jülich, Germany

64. Bibliothek, KfK Karlsruhe GmbH, Postfach 3640, D-7500 Karlsruhe 1, Germany 
65. Bibliotheque, Centre de Recherches en Physique des Plasmas, Ecole Polytechnique Fédérale de Lausanne, 21 Avenue des Bains, CH-1007 Lausanne, Switzerland

66. Bibliothèque, CEA/Cadarache, F-13108 Saint-Paul-lez-Durance Cedex, France

67. Library, JET Joint Undertaking, Abingdon, Oxfordshire OX14 3EA, England

68. Library, FOM-Instituut voor Plasmafysica, Rijnhuizen, Edisonbaan 14, 3439 MN Nieuwegein, The Netherlands

69. Library, National Institute for Fusion Science, Chikusa-ku, Nagoya 464-01, Japan

70. Library, International Centre for Theoretical Physics, P.O. Box 586, I-34100 Trieste, Italy

71. Library, Centro Richerche Energia Frascati, C.P. 65, I-00044 Frascati (Roma), Italy

72. Library, Plasma Physics Laboratory, Kyoto University, Gokasho, Uji, Kyoto 611, Japan

73. Plasma Research Laboratory, Australian National University, P.O. Box 4, Canberra, A.C.T. 2601, Australia

74. Library, Japan Atomic Energy Research Institute, Naka Fusion Research Establishment, 801-1 Mukoyama, Naka-machi, Naka-gun, Ibaraki-ken, Japan

75-113. Given distribution as shown in DOE/OSTI-4500-R75 under category UC-420, (Magnetic Fusion Energy) 